\title{
KIDS OR COURSES? GENDER DIFFERENCES IN THE EFFECTS OF ACTIVE LABOR MARKET POLICIES
}

\author{
Michael Lechner and Stephan Wiehler* \\ University of St. Gallen, Swiss Institute for Empirical Economic Research (SEW), \\ Varnbüelstrasse 14, CH-9000 St. Gallen, Switzerland, Fax: +49 71224 2302, \\ Michael.Lechner@unisg.ch, Stephan.Wiehler@unisg.ch. \\ This version: June, 2009 \\ Date this version has been printed: 23 June 2009
}

\begin{abstract}
We investigate active labor market programs in Austria. We find only small effects, if any, for most of the programs. However, the programs may have unintended consequences for women. In particular for younger women, a key effect of the programs and one reason for the male-female effect differential that is observed in the literature is to reduce or postpone pregnancies and to increase their attachment to the labor force. Furthermore, the variables capturing pregnancies and times of parental leave play a key role in removing selection bias.
\end{abstract}

JEL classification: J68

Keywords: Active labor market policy, matching estimation, program evaluation, panel data.

\footnotetext{
The first author is also affiliated with ZEW, Mannheim, CEPR, London, IZA, Bonn, PSI, London, and IAB Nuremberg. Financial support by the Austrian Federal Ministry of Economics and Labor (BMWA) and by the European Commission is gratefully acknowledged. We benefited from many helpful comments from Johannes Schweighofer, Gottfried Wetzel (both BMWA), and from Helmut Mahringer (Austrian Institute of Economic Research). The data were prepared in cooperation with Helmut Scheer from SIEMENS Austria. A previous version of the paper has been presented in workshops at the BMWA in Vienna, at the Universities of Aarhus, Freiburg, and St. Gallen, and at IAB, Nuremberg, and SOFI, Copenhagen. We are grateful to the participants of those workshops for their helpful comments and suggestions. Furthermore, three anonymous referees helped to improve a previous version of the paper considerably. The usual disclaimer applies. Michael Lechner is the corresponding author.
} 


\section{Introduction}

There seems to be a consensus emerging that women benefit more from labor market programs than men, e.g. see the surveys by Bergemann and van den Berg (2006) for Europe and Heckman, LaLonde, and Smith (1999) for the US. Our comprehensive evaluation of the Austrian active labor market programs shows that the effect differentials disappear once information on pregnancies and parental leave is incorporated or once the analysis is focused on unemployed with age above 40 years, where pregnancies and parental leaves are hardly an issue anymore.

Many recent European studies have emphasized the role of effect heterogeneity on the program level. ${ }^{1}$ In terms of participant heterogeneity Puhani (1999) and Kluve, Lehmann, and Schmidt (1999, 2008) find sex specific program effects for Poland. Friedlander, Greenberg, and Robins (1997) and Heckman, LaLonde, and Smith (1999) feature sex differences for the US and other western economies. Lechner, Miquel, and Wunsch (2009) look at employment effects for certain subgroups of participants in West Germany. They find effect heterogeneity with respect to residence, previous occupation, and sex. For East Germany, Lechner, Miquel, and Wunsch (2007) find that for some training programs the employment effects for women were much larger than for men. They attributed this heterogeneity to specifics of the selection process that resulted in a higher probability of men being trained with skills for the construction sector which then collapsed. However, such a precise identification of the reasons for gender differences is not always possible and the puzzle remains in many other studies. Bergemann and van den Berg (2006) survey 15 studies on effect differentials for men and women in Europe. 13 of those studies report effect premia for women. Heckman, LaLonde, and Smith (1999) survey 16 studies for the US and also provide broad evidence for effect premia for women in terms of earnings. The key explanations that are put forward are gender differences with respect to labor supply elasticity, eagerness to learn, responsiveness 
to wage changes, and with respect to the larger choice set for women, i.e. including times of parental leave in addition to work and leisure. Their overall conclusion is that labor market programs seem to work better for women in countries where the female labor force participation rate is relatively small, which is also the case in Austria.

Due to a unique and informative data base of the Austrian labor force, we show that those estimated differentials between men and women consist of two components. The first component is a selection bias due to the lack of controlling for the occurrence of pregnancies before or at the start of the programs, leading to more pregnancies in the group of nonparticipants than in the group of participants. Thus, estimated effects that ignore this information show biases in favor of the programs. Second, the remaining differential in the employment effect appears because program participation postpones or reduces fertility, which in turn implies that programs have an adverse effect on other policies that are designed to foster birth rates. Once those two components are accounted for, the effect heterogeneity between men and women can be explained. In that context it is interesting to note that information on pregnancy status has not been available in many studies surveyed by Bergmann and van den Berg (2006). In addition, one third of those studies even lacked information on dependent children. Thus, linking our findings to the latter study, we demonstrate that in countries like Austria with a low female labor force participation rate, ${ }^{2}$ it is even more important to have information about the outside opportunities of women, in particular times of parental leave.

The underlying data are made available by the Federation of Austrian Social Insurance Institutions and the Austrian Public Employment Service. We possess a rich set of information on the employment history, times of unemployment, the counseling process, personal characteristics, parental leaves, and times of program participation as well as regional characteristics. Assuming conditional independence of the selection mechanism and potential outcomes, we employ an advanced version of a semi-parametric matching estimator that is very popular in 
the policy evaluation literature and was used previously, for instance, by Lechner, Miquel, and Wunsch (2009).

The paper is organized as follows. Section 2 briefly summarizes the institutional background of the Austrian labor market policy. Section 3 introduces the underlying data and identification strategy as well as a first description of the population of interest. The estimation method and first results of the program allocation analysis can be found in Section 4. Section 5 shows estimation results and omitted variable checks and Section 6 concludes. Details concerning the data, the estimation method, and results are provided in an internet appendix that can be downloaded from www.sew/lechner/at.

\section{$2 \quad$ Labor Market Policies in Austria}

The Public Employment Service Act constitutes the legal foundation of the Austrian labor market policy. It determines the objectives of the Public Employment Service by defining the following six principles. (i) The Public Employment Service has to match job seekers and vacancies efficiently, (ii) remove any barrier that prevents this matching, (iii) increase the flow of information about potential matches, (iv) mitigate quantitative and qualitative differences between labor demand and supply, (v) secure sustainable employment, (vi) and provide funds for the unemployed in case of a job loss. As many other countries, Austria uses active and passive labor market policies to implement those principles.

\subsection{Passive labor market policy}

Passive labor market policy in Austria is designed to cover earnings losses caused by various types of non-employment. To receive unemployment benefit payments the unemployed have to be registered at the Public Employment Service, be eligible and willing to work, and have a predefined record of employment with unemployment insurance (UI) contributions. The preunemployment employment requirement is a cumulated UI contribution period of 52 weeks 
within the last 24 months for the first draw on benefits. Subsequent benefits require 28 weeks within the previous 12 months. Exceptions regarding age exist. ${ }^{3}$ The standard replacement ratio is 55 percent of the former net income and the minimum entitlement period is 20 weeks. Extra payments depending on family status and the number of children may be added. After unemployment benefits expire, the unemployed are entitled to unemployment assistance, if they are still available for work. Unemployment assistance payments are means-tested, but are not subject to a time limit.

\subsection{Parental leave subsidies}

There are three different types of subsidies for women in parental leave. Eight weeks before and after the scheduled confinement women receive so-called confinement benefits, which are granted up to the average net wage of the previous three months. ${ }^{4}$ After the expiration of those benefits (and before January 2002), women had to apply for parental leave benefits. This benefit was granted subject to the same UI contribution requirements as unemployment benefits, which excluded women who failed to prove the required previous contribution times. ${ }^{5}$ After January 2002, women may apply for childcare benefit which is no longer linked to previous contribution times and granted to everyone with an amount of 14.53 Euro a day for a maximum period of 30 months. ${ }^{6} 18$ months of this entitlement period are counted as regular contribution times to the pension schemes. All periods in which such benefits have been paid out are recorded in the social security records. Therefore, this information is available in the current study. We use this information to construct the theoretical start date of a pregnancy by employing the usual 9-month pregnancy period as illustrated in Figure 1.

Figure 1 about here 


\subsection{Active labor market policy}

Apart from counseling and placement services there are a variety of active labor market programs offered by the Public Employment Service in order to overcome specific reintegration obstacles of the unemployed.

The first group of programs promotes vocational flexibility. Those programs can be classified into orientation measures, active job search, job coaching, and qualification measures. Orientation measures assess the individual situation and aptitude of the unemployed person and serve as an upfront decision process for subsequent (re-)integration activities. Active job search aims at improving job acquisition skills, like writing an application or interview training. Job coaching deals with the long-term unemployed and groups with specific placement handicaps, like disabled persons, by means of a combination of counseling, qualification, and on the job training. Qualification measures comprise further education and various forms of vocational training. The range of program stretches from courses requiring only basic skill levels, like catering courses, to high level software courses, up to formal educational and vocational degrees. Participants are either allocated by the Public Employment Service or find a program on their own and then apply for course subsidies with the Public Employment Office.

Another group of programs consists of the so-called job creation schemes. Socio-economic enterprises and non-profit sector projects are designed to capture the long-term unemployed individuals and other problematic cases, like, for instance, individuals with psychological diseases, etc. Such programs offer a quasi-realistic work environment. In principle, those jobs are restricted to one year. They are sometimes augmented by socio-pedagogical treatment to gradually reintegrate the participants into the regular labor market. With integration subsidies, the Public Employment Service supports special groups of unemployed, like the disabled, long-term unemployed or older people, by means of a wage subsidy for the first 150 days of a 
new employment. Encouraging individuals to become self-employed, the Public Employment Service offers the so-called business start-up program, which supports young entrepreneurs, starting with a business idea until the actual foundation of their own firm. Furthermore, the Public Employment Service supports young individuals who have been searching unsuccessfully for an apprenticeship by providing different courses aimed at endowing the participants with human capital that is similar to the level of the first year of a regular apprenticeship of three years. A hybrid form of labor market programs is the so-called beneficence for labor, which is organized in collaboration with local firms in order to compensate sudden local excess demand or supply of workers caused by, e.g. business foundation or sudden firm closures. ${ }^{7}$ Finally, there are also qualification programs for employees to enhance sustainable employment for workers threatened by unemployment.

Table 1 about here

To get an impression of the magnitude of the programs, Table 1 reports the overall expenditures and number of participants per program type. It can be seen that active job search and qualification measures are the most important programs with respect to the number of participants. Over time, we observe that the number of active job search programs increases whereas participation in qualification measures drops to 70 percent in 2002 compared to 2000. Integration subsidies feature far less participants but a considerable amount of expenditures, because the respective subsidies can amount up to 100 percent of the wage bill of the new employment. The same holds for socio-economic enterprises and non-profit sector projects which are also characterized by high average costs per participation of, for instance, over 11'000 Euros for non-profit sector projects in 2000. In contrast, course subsidies appear to be on average a rather low-cost measure of around 600 Euros per participation in $2000 .^{8}$ For the year 2002, we also calculated expenditures per day. Again, we can see that socioeconomic enterprises, non-profit sector projects, and integration subsidies are the most 
expensive measures per day. The former two are even more costly since the respective expenditures do not only cover the wage of the participants, but also the coverage of potential losses of the job-creating firm. Beneficences for labor have very low costs per day since most of the costs are carried by the cooperating firms.

\section{Data and identification strategy}

\subsection{Data}

The three data sources that are used for the program evaluation comprise administrative registers from the Federation of Austrian Social Insurance Institutions and the Austrian Public Employment Service, including information from the program register data. We make use of all the Austrian population instead of a random sample as is usually the case. Using the population increases computation time considerably, but maximizes the precision of our evaluation results. For example, due to the resulting large number of observations, it will be possible to non-parametrically estimate program effects fairly precisely even for smaller subgroups of participants and programs.

We use the Social Insurance data to obtain information about times in employment (employment states: employed, self-employed or civil servants; with earnings and employer information), retirement, and other periods relevant for social insurance contributions from 1985 to 2005. Since all financial support during times of parental leave are granted relative to the scheduled confinement date, we identify not only times of parental leave, but also the pregnancy status for women, which will be a key control variable in the analysis. Information about the counseling process of the Public Employment Service, i.e. beginning and end of an unemployment period, regional identifiers, personal characteristics like sex, marital status, nationality, current profession and desired profession, education, disability status, number of job offers received, or times of previous labor market program participation, is available from 
the Public Employment Service data from 1990 until 2005. Finally, the Public Employment Service data gives us detailed information about the type of labor market program from 2000 to 2005 .

Most of the data is available on a daily basis, but to condense the information into a manageable form we chose to aggregate the daily information into 2 week intervals (which is more precise than the usual grids used by evaluation studies that are commonly based on monthly, quarterly or even yearly information).

However, although this data set is well suited for an evaluation exercise, the nature of the data nevertheless imposes some restrictions with respect to the definition of the participation window and the follow-up period which will be discussed in detail later on. Furthermore, we have to rely on a quite broad definition of the type of qualification measures ${ }^{9}$.

\subsection{Identification strategy}

In the current analysis, we concentrate on the average program effects compared to nonparticipation. The identification problem in non-experimental program evaluations is that participants in one program differ, sometimes substantially, from potential comparison observations in the non-participation state with respect to characteristics that may influence the outcome variables under inspection as well. Since our data is very informative, but contains no obvious instrumental variable, i.e. a variable that influences the outcome only by influencing the participation decision, we chose the so-called conditional independence assumption (CIA) to overcome the resulting identification problem. It states that if we are able to observe all factors that jointly influence the participation decision and the outcomes, then, conditional on those factors, we can learn the (potential) non-participation outcomes of the participants from the observable non-participation outcomes of the non-participants with the same distribution of characteristics, which identifies our parameter of interest. This identification strategy goes back to Rubin (1974) for the case of comparing participants to 
nonparticipants. Imbens (2000) and Lechner (2001) generalize this idea to the case of multiple treatments and provide similar identification conditions. However, the CIA strongly hinges on the availability of a comprehensive set of covariates. To justify its applicability in the present framework, we now discuss three important issues of program allocation: the allocation decision of the caseworker of the Public Employment Service, the willingness and collaboration of the unemployed individual, as well as relevant eligibility criteria in general.

The standard allocation procedure is initially based on a face-to-face interview between the unemployed person and the caseworker. Several aspects, like education, family affairs, past behavior on the labor market, features of the last employment, and individual program history are discussed. As a result of this interview and in light of the local characteristics of the labor market, the caseworker decides whether or not the unemployed person should be sent into a specific labor market program. Multiple refusals of program offers can lead to temporary suspensions of the benefit payments. However, such punishments are rarely observed in the data. The data contains a large set of covariates that are suitable to map most of those aspects. In addition to variables like age, sex, foreigner status, family status, education, information on the job, and the previous sector of employment, we construct a rich set of variables that summarizes the entire labor market history of the unemployed person. This history covers up to 15 years before the actual entry into unemployment under inspection on a fine 2-week scale. We construct variables covering previous times of (un-) employment, program participation, times of childcare ${ }^{10}$, military service, times of non-registration, which we call out-of-labor-force times (OLF) from now on. By means of this, we are also confident to possess suitable proxy variables for unobservable variables like motivation or the general attitude towards employment. In addition, we use characteristics of the local labor markets relevant for each specific individual. ${ }^{11}$ 
From the perspective of the unemployed, all points mentioned above, certainly play a role for the participation decision. Another component of the individual consideration might be the question whether the currently unemployed person was satisfied with the kind of his/her former job. Since we observe data on the current and the desired profession, we are able to identify or at least approximate this feature. Furthermore, since unemployment insurance contributions are paid during the time of program participation, the individual decision might take into account the remaining time of the unemployment benefits. Thus, we also compute the remaining unemployment benefits claim at the time of (hypothetical) program entry. Another important determinant will certainly be the existence of dependent children, which is available in this data. Thus, we control for all previous times in parental leave (and thus for the complete childbearing history), but also for the month of pregnancy for women during the unemployment spell under consideration, i.e. the pregnancy status right before the hypothetical program entry, which has not been available in previous studies on effect differentials for men and women. Furthermore, we asses all previous control variables to be also relevant for the outcome variable 'parental leave' which is used later on, especially, age, marital status, and education. The desire for vocational change is also a key determinant, since unemployed who desire a vocational change are presumable less focused on family planning.

From an institutional point of view, a key eligibility requirement for program participation is being unemployed (whether the individual receives unemployment benefits or unemployment assistance is irrelevant). We will resolve this issue by choosing an adequate inflow of eligibles into unemployment. Finally, there are number of guidelines that define specific types of unemployed to receive preferential treatment in certain programs. We explicitly account for this by tailoring the selection models to the comparisons of the specific programs under consideration, i.e. using flexible specifications that include key determinants for the selection into the respective programs. Overall, we plausibly pin down most important factors that drive 
the allocation decision and the potential outcomes. Thus, assuming CIA appears to be a credible identification strategy.

\subsection{Definition of the population and the programs of interest}

To be included in our evaluation, programs and the respective participants have to meet five requirements. First, the identification strategy strongly hinges on the existence of a long labor market history before the entry into unemployment. Second, the follow-up period after program attendance should not be influenced by perturbing events like the possibility of (early) retirement. As a result of those arguments, we concentrate on the age groups of the labor force between 25 and 50 years. Third, the data must provide all relevant information about the selection into the different labor market programs. Fourth, since we employ non-parametric estimation techniques, the number of observations in the different programs has to be sufficiently large. Finally, we require the program content to be more substantial than the usual counseling process. Under those restrictions, we end up with six program types that can be credibly evaluated: Socio-economic enterprises, non-profit sector projects, job coaching, active job search, qualification measures, and course subsidies.

The nature of the data drives the definition of the population used in the estimation. Information on program participation is only available from the year 2000 onwards. The follow-up period is restricted by the end of the observation period in 2005. Hence, we consider the first inflow of individuals ${ }^{12}$ from employment into unemployment or one of the six labor market programs between 2000 and 2002. ${ }^{13}$ By means of this, we observe enough participants in each program and have a follow-up period of at least three years, which enables us to identify effects that are less affected by initial lock-in effects. Doing so, we end up with a population of 797'034 persons.

The next step is to divide all persons who passed this criterion into participants and nonparticipants. In that population, we define a participant to be a person who took part in a program 
before the end of 2002 (without an employment spell between inflow and participation). Thus, nonparticipants are persons who moved from employment into unemployment and have not been allocated to a program between 2000 and 2002, or took up an employment before being allocated to a program. The resulting numbers of observations are shown in the first row of Table 2.

Table 2 about here

However, we impose a number of further restrictions. Some control variables, like the remaining unemployment insurance benefit claim or the duration in unemployment before the entry into a program require a reference data (artificial program start date) for the nonparticipants. To obtain such a reference date, we employ an approach suggested by Lechner (1999). We simulate start dates for the nonparticipants by drawing start dates from the distribution of the participants. If the nonparticipant is not eligible at the simulated reference date, then this nonparticipant is not considered in the evaluation. The fairly drastic reduction in the number of observations is not particularly important though, since (i) participants are in abundant supply, and (ii) they serve only as comparison observations for participants and are not interesting per se. In Austria, temporary layoffs are widely spread. Especially workers in the tourism or construction sector are laid off with a more or less binding reemployment guarantee. Since such reemployment guarantees may differ substantially with respect to how much binding they are, and since we do not observe such differences that most likely influence participation and labor market outcomes, we require that all persons are laid off permanently. The age restriction, for reasons described above, is applied as well. Furthermore, we require the duration of the last employment before the inflow into our sample to be longer than 2 months. By means of this, we make sure that prior participants in subsidized employment are not employed further for a couple of days after the end of the program, which would cause a short employment spell before becoming unemployed again. We observe that especially the 
age restriction reduces the number of participants and nonparticipants considerably. The resulting number of observations, however, still allows reliable results from non-parametric estimation.

\subsection{A descriptive analysis of the selection into the programs}

As a first description of the selection process, Table 3 shows mean characteristics by participation status for selected variables. ${ }^{14}$ In general, the numbers exhibit many aspects of the institutional environment in Austria as well as the general allocation policy of the Public Employment Service. Except for socio-economic enterprises and active job search the fraction of female participants is above 50 percent. Qualification measures even have a female participation rate of $62 \%$ which underlines gender mainstreaming requirements anchored in the Guiding Principles of the Federal Ministry of Economics and Labor. Consequently, those participants feature higher average mean durations in times of parental leave before the defining unemployment period. We computed the pregnancy state for women right before the hypothetical program start. It can be seen that pregnancy is hardly an issue for the program groups, except for non-profit sector projects. Further, we observe that the fraction of pregnant female non-participants is higher compared to female participants of all programs, so that pregnancy status is indeed an important variable to control for in the remainder of the analysis.

For programs which are specifically designed for unemployed with certain reintegration obstacles, like socio-economic enterprises, non-profit sector projects and job coaching, we observe a fraction of disabled participants of almost 22 percent which is nearly three times higher than for active job search and more than two times higher than for qualification measures and course subsidies. Participants of socio economic enterprises are also on average the oldest and the ones with the shortest mean duration in childcare. This distinction between programs for unemployed with stronger reintegration problems on the one hand and programs for unemployed with 'usual' reintegration problems on the other hand can be observed in 
many dimensions. For the former group we observe predominantly participants with compulsory schooling (9 years) as the highest education level, jobs in the production and construction sector, higher average times in unemployment, shorter durations of the last employment spell and a lower overall fraction in employment over the entire observation period in the data. Furthermore, those participants have much lower remaining benefit claims at the time of program entry and lower past earnings.

Table 3 about here

A peculiarity that is observed for all program groups is that $15-23$ percent of the participants attended a program of the same kind in a previous unemployment spell. Active job search measures, primarily used to endow participants with special job application and interview skills, are also used as a screening instrument for long-term unemployed in order to renew and tighten the contact to the local Public Employment Service office. This is also reflected in Table 3 since participants in active job search live in regions with a higher average fraction of long-term unemployment. It can be observed that non-profit sector projects and job coaching are rarely used in the state of Vienna compared to the rest of Austria. In terms of employment in the period after the program, we find that participants in socio-economic enterprises, nonprofit sector projects, and job coaching have considerably lower employment rates one year after the program start, which is not surprising given program lengths of up to one year. Participants in shorter programs exhibit higher employment rates. Overall, participants catch up after two or three years.

Figure 2 about here

Figure 2 provides a more complete picture of pre- and post-program employment rates. The abscissa shows the months before and after the (hypothetical) start of the program. The ordinate measures the employment rate for different program groups. The left picture shows that participants in socio-economic enterprises, non-profit sector projects, and job coaching 
differ quite substantially from nonparticipants with respect to their employment history three years before the program. Hence, interpreting post-program employment rate differences as program effects is not appropriate. The same holds for active job search, qualification measures, and course subsidies. Here, the pre-program differences are also visible, but not as large as for the first group of programs.

\section{Econometric methodology}

As discussed before, the identification of the program effects hinges on the existence of the variables that jointly influence program participation and potential outcomes. For every comparison of different program states (including nonparticipation) the estimation strategy is to form comparison groups that do not differ from the respective program groups with respect to the distribution of those conditioning variables. We employ an advanced version of a semiparametric two stage propensity score matching approach. This class of estimators is popular in the program evaluation literature, because it allows for individual effect heterogeneity while not requiring a parametric specification for the relation of the outcome variable and the variables controlling for the selection bias correction. Rosenbaum and Rubin (1983) show that if the CIA holds, given all relevant covariates, then it also holds for a particular scalar function of those covariates, i.e. the participation probability conditional on the control variables (propensity scores). Hence, a first-step procedure estimates those conditional program participation probabilities. The advantage is that the construction of control groups can be done on the basis of the propensity score. Those points are discussed in Heckman, LaLonde, and Smith (1999) and Imbens (2004) for the binary treatment and in Imbens (2000) and Lechner (2001) for the multiple treatment case.

We model the propensity score by means of binary probit models for each program type and for men and women separately. The specifications differ sometimes considerably by program and gender as can be seen in the internet appendix. The results give further insights into the 
program allocation of the caseworkers. Table 4 reports a selection of variables that appear frequently in all specifications. ${ }^{15}$ Despite the existence of considerable heterogeneity, some general determinants of program participation versus nonparticipation appear. For both sexes we find a positive relation of participation to disability, desiring a vocational change, longer durations of the defining unemployment spell, and having higher average durations in past employment. Jobs in the law and administration and trade sector tend to increase the probability of being promoted in active job search, qualification measures and course subsidies. Being a foreigner, having a university (entrance) degree, as well as a previous occupation in the service sector decreases (if at all) the participation probability. For women, we find that the months of pregnancy reduce the participation probability for all programs, except socio-economic enterprises. The overall previous time spent in parental leave prior to the defining unemployment spell under consideration reduces the participation probability for non-profit sector projects, job coaching, and active job search, but increases the one for course subsidies. For men, we find that having no vocational degree increases the probability of participating in socio-economic enterprises, non-profit sector projects, and active job search, but decreases the one for participating in course subsidies. The remaining picture is less clear as can be seen in Table 4.

To obtain the final estimates of the program effects, we use the extended propensity score matching procedure as proposed by Lechner, Miquel, and Wunsch (2009) and modified by Wunsch and Lechner (2007). First, they allow for more than one good match, if available, by incorporating the idea of caliper matching as in Dehejia and Wahba (2002). Second, they incorporate a bias correction procedure to account for small mismatches of the matching step by exploiting the double robustness property as discussed in Rubin (1979) and Joffe, et al. (2004). The appendix contains a brief description of the way the estimator is implemented. 


\section{Results}

\subsection{Program effects by gender}

The following figures illustrate program effects for participants in one program (listed at the top of each figure) compared to nonparticipation. The follow-up period relevant for outcome measurements starts at the day of program entry and ends three years later. Effects are estimated monthly as differences of percentage points for all outcome variables. ${ }^{16}$ If symbols appear on the different lines (denoting the program effects), it means that the respective effects are statistically different from zero at the 5 percent level. Recall that the matching step is done on the basis of propensity scores that are estimated for men and women separately. ${ }^{17}$

The two graphs in the first row of Figure 3 show employment effects of participating in socioeconomic enterprises, non-profit sector projects, and job coaching. Common to all graphs of Figure 3 are negative employment effects for all programs right after the start, which is commonly labeled as lock-in effect (see van Ours 2004, among others). The intuition is that participants reduce their search intensity while being in a program and, therefore, re-enter less frequently into regular employment than non-participants. There are differences in the progression of the curves for men and women. For women, we observe that socio-economic enterprises seem to increase the employment probability of the participants by 9 percent after three years. For qualification measures and course subsidies, presented in the second panel of Figure 3, we find small positive effects at the very end of the follow-up period of about 2.5 percent for women. ${ }^{18}$ For male participants, we do not find positive effects for any program. Qualification measures even seem to harm the respective participants three years after program start. Interestingly, even after controlling for the pregnancy status which distinguishes this study from previous ones, we still find some positive effects after three years for women. Thus, for certain labor market programs this study points to an effect premia for women as well. ${ }^{19}$ 
Figure 3 about here

\subsection{Where do the positive effects for women come from?}

Previous studies, like Lechner, Miquel, and Wunsch (2009), showed that usually the positive employment effects are not achieved by reducing the rate of registered unemployed participants, but by increasing their labor force attachment, i.e. by reducing the rate of participants leaving the labor force. Therefore, Figure 4 shows the program effects on times out of the labor force (OLF), defined as not being employed and not being registered as unemployed in the current study.

Figure 4 about here

All programs reduce times in OLF. Comparing both sexes, especially in the lower panel of Figure 4, we find the reduction of OLF to be higher for women than for men. Using a unique feature of our data, we disaggregate this effect further. Figure 5 shows the program effects on times of parental leave for men and on times of parental leave plus pregnancy (PP) for women. ${ }^{20}$ For women, we find significant negative effects on PP for qualification measures and course subsidies.

Figure 5 about here

For socio-economic enterprises, job coaching, and active job search we also find negative, but insignificant effects. Only non-profit sector projects seem to have small positive effects on PP, though being insignificant. There are no significant effects on parental leave for men. To summarize, women who are not allocated to a labor market program, though being eligible, switch more frequently into PP. It seems as if some of those women are faced implicitly with the decision of being trained or using the time to realize family plans that would have been postponed otherwise, i.e. in case of a program allocation. Hence, we find that apart from effects on employment (positive or negative) programs may contradict other policies that are 
designed to increase birth rates. As a final check, we use an outcome variable which takes the value one for times in employment and PP and zero otherwise. The results are presented in Figure 6.

Figure 6 about here

The result is rather striking. Three years after program start we do not find any significant effect for any program type, neither for men nor for women. Moreover, we observe that the relative dominance of the women melted down towards zero. It appears that the only remaining difference appears for qualification measures with significant negative effects for men and insignificant effects for women. Hence, we do not find substantial effect premia for women as soon as we incorporate times of PP as an outcome variable. The female-premia in Figure 3 appeared because female non-participants take an additional outside opportunity, i.e. becoming a mother, which leads to comparably low employment rates for this pool of women. Men are much less affected by such issues and we, therefore, observe only the program effect, which is usually non-positive.

From the perspective of the policy maker, the message of the results should be ambiguous. If additional kids are considered as desirable as employment, then the programs are ineffective. If not, then the increase in the employment effect for women at the cost of reducing or postponing fertility may be desirable and considered as a 'positive' outcome of the active labor market policies.

Figure 7 about here

Due to the large size of the population in this study, it is possible to stratify female participants further, i.e. per age group, to get a clearer picture of the underlying heterogeneity relating to this effect. Thus, we divide all women into two age groups, below and above 40 years, to separate two groups that differ with respect to individual family plans. Doing so, 97.6 percent of all pregnancies just before the hypothetical program start are in the lower age group. 
Due to population size restrictions, we consider the three larger programs only, active job search, qualification measures, and course subsidies.

Figure 8 about here

Figure 8 shows that splitting the female population according to age, we observe that the positive effect for course subsidies can be attached to women younger than 40 years. For this group we observe that all programs have a negative effect on PP. For the older segment in turn, we do not observe such effects. Overall, for both age groups we fail to detect positive effects once we take employment plus PP as the outcome variable. Additionally, but not surprisingly, the effects on employment for men above the age of 40 look exactly like the effects for women in that age group since pregnancies and parental leaves play hardly any role here. ${ }^{21}$ Both arguments confirm our result that once we correct for the selection bias (pregnancy status for women) the remaining (small) positive effects, here for course subsidies for younger women, only appear because eligible non-participants subsequently emphasize family planning, which leads to lower employment rates compared to those participants they have been matched to.

\subsection{Pregnancy bias - a sensitivity check for omitted variables}

As became clear in the previous section, one important feature of this study is that we use information on parental leave and pregnancies as an outcome variable as well as for correcting for potential selection bias, as pregnant women are rarely observed in labor market programs. Thus, if this variable is not controlled for, it is likely that a larger share of pregnant women appears in the group of nonparticipants which will bias the employment effects upwards.

Now, we analyze the size of this bias by comparing our results to results that would have been obtained without that information. First, we do not delete persons who are in parental leave right before the (hypothetical) program entry and, second, we leave out the month of preg- 
nancy from the selection model, i.e. we allow for the selection bias that we suspect to be one driving factor for the positive effect differential for women. Figure 9 summarizes the results.

Obviously, the results for men are not affected by this change since parental leave is a minor issue here. For women, all effects increase by approximately 2-3 percentage points compared to Figure 3. For socio-economic enterprises this results in a wider range of significant positive effects, especially at the end of the follow-up period. For active job search, qualification measures, and course subsidies we now observe significant positive effects that are stable from the middle of the follow-up period onwards. According to these estimation results we would conclude that we find clear evidence of positive effects for women for four out of six labor market programs, which is highly misleading as shown by the results in the previous sections.

Figure 9 about here

To wrap up, we find two important impacts of the observability of times of parental leave. First, by constructing the pregnancy status for women, it removes the remaining omitted variable bias in the first-step selection model. Second, it can be used to better understand program effects in the follow-up period.

\section{Conclusion}

This study provides an econometric evaluation of several important active labor market programs in Austria. Large and informative administrative data is used to control for potential selection problems. As a particular advantage of the data, we identify times of pregnancy and parental leave. For women, this information turns out to be very important for reducing selection bias as well as for understanding the effects of the programs.

For men, we find the programs to be generally ineffective in increasing unsubsidized employment. However, without controlling for pregnancy status, most programs appear to be 
effective in increasing employment prospects for women. Those effects become smaller once the pregnancy information is taken into account, but they are still there. A closer investigation shows that the programs increase female employment by reducing the share of women leaving the labor force. The underlying mechanism is that the programs reduce the pregnancy rate of the participants, i.e. programs also have an adverse (and often unintended) effect on other policies designed to foster birth rates. Once that effect is subtracted from the employment effects, almost all gender differences disappear.

Our findings about the gender differences may explain results appearing in the survey by Bergemann and van den Berg (2006). They find that women's effect premia predominantly occur in countries with a low female work force participation indicating that times for taking care of infants and labor market participation are less compatible or exclusive. Moreover, none of those studies incorporated information on times of pregnancies. We demonstrate for the case of Austria that it is important to have information about the outside opportunities of women, like times of parental leave. The puzzle of women's effect premia might be partially explained by the fact that important confounders (and outcome measures), like the ones discussed above, have not been available in other studies. ${ }^{22}$

The question whether our results for women, namely a positive employment effect and a zero effect on the fertility plus employment outcome, indicate that the definition of a program success depends on the value judgement of the policy makers. If additional (or earlier) kids are considered as desirable as employment, then the programs are ineffective. If employment is considered more important, then the increase in the employment effect for women at the cost of reducing or postponing fertility may be desirable and considered as a 'positive' outcome of the Austrian active labor market policies. This conclusion is most likely true not only for Austria, but for many other European countries as well. 


\section{References}

Bergemann A, van den Berg G (2006) Active Labor Market Policy Effects for Women in Europe: A Survey. Discussion Paper 2365, Institute for the Study of Labor (IZA).

Caliendo M, Hujer R, Thomsen S (2004) New Evidence on the Effects of Job Creation Schemes in Germany - A Matching Approach with Threefold Heterogeneity. Research in Economics 58: 257-302.

Caliendo M, Hujer R, Thomsen S (2005) The Employment Effects of the Job Creation Schemes in Germany: A Microeconometric Evaluation. Discussion Paper 1512, Institute for the Study of Labor (IZA).

Caliendo M, Hujer R, Thomsen S (2008) Identifying Effect Heterogeneity to Improve the Efficiency of Job Creation Schemes in Germany. Applied Economics 40: 1101-1122.

Caliendo M, Hujer R, Thomsen S (2006) Sectoral Heterogeneity in the Employment of Job Creation Schemes in Germany. Jahrbücher für Nationalökonomie und Statistik 226: 139-179.

Carling K, Gustafson L (1999) Self-Employment Grants vs. Subsidized Employment: Is There a Difference in the Re-Employment Risk?. Working paper, Institute for Labor Market Policy Evaluation (IFAU).

Carling K, Richardson K (2004) The Relative Efficiency of Labor Market Programs: Swedish Experience from the 1990s. Labor Economics 11: 335-354.

Dehejia R, Wahba S (2002) Propensity Score-Matching Methods for Nonexperimental Causal Studies. The Review of Economics and Statistics 84: 151-161.

Forslund A, Johannson P, Lindqvist L (2004) Employment Subsidy - A Fast Lane from Unemployment to Work?. Working Paper 2004:18, Institute for Labor Market Policy Evaluation (IFAU).

Friedlander D, Greenberg D, Robins P (1997) Evaluating Government Training Programs for the Economically Disadvantaged. Journal of Economic Literature 35: 1809-1855.

Gerfin M, Lechner M (2002) A Microeconometric Evaluation of the Swiss Active Labor Market Policy. The Economic Journal 112: 854-893.

Gerfin, M, Lechner M, Steiger H (2005) Does Subsidized Temporary Employment Get the Unemployed Back to Work? An Econometric Analysis of two Different Schemes. Labour Economics - An International Journal 12: 807-835.

Heckman JJ, LaLonde R, Smith J (1999) The Economics and Econometrics of Active Labor Market Programs, vol. III A of Handbook of Economics. North-Holland, Amsterdam.

Hofer H, Weber A (2004a) Are Job Search Programs a Promising Tool? A Microeconometric Evaluation for Austria. Discussion Paper 1075, Institute for the Study of Labor (IZA).

Hofer H, Weber A (2004b) Employment Effects of Early Interventions in Job Search Programs. Discussion Paper 1076, Institute for the Study of Labor (IZA).

Hujer, R., S. Thomsen, and C. Zeiss (2005): "The Effects of Vocational Training Programmes on the Duration of Unemployment in Eastern Germany," Working paper, Goethe University Frankfurt.

Imbens, G (2000) The Role of the Propensity Score in Estimating Dose-Response Functions. Biometrica 87: 706-710. 
Imbens, G (2004) Nonparametric Estimation of Average Treatment Effects Under Exogeneity: A Review. The Review of Economics and Statistics 86: 4-29.

Joffe, M, Ten Have T, Feldman H, Kimmel S (2004) Model Selection, Confounder Control, and Marginal Structural Models. The American Statistician, 58 (4): 272-279.

Kluve, J, Lehmann H, Schmidt C (1999) Active Labor Market Policies in Poland: Human Capital Enhancement, Stigmatization, or Benefit Churning?. Journal of Comparative Economics 27: 61-89.

Kluve, J, Lehmann H, Schmidt C (2008) Disentangling Treatment Effects of Labor Market Policies: The Role of Employment Histories. Labour Economics 15: 1270-1295.

Lalive, R, van Ours J, Zweimüller J (2008) The Impact of Active Labor Market Programs on the Duration of Unemployment. Economic Journal 118: 235-257.

Lechner, M (1999) Earnings and Employment Effects of Continuous Off-the-Job Training in East Germany After Unification. Journal of Business \& Economic Statistics 17: 74-90.

Lechner, M (2001): Identification and Estimation of Causal Effects of Multiple Treatments under the Conditional Independence Assumption. Physica / Springer, Heidelberg.

Lechner, M, Miquel R, Wunsch C (2009) Long Run Effects of Public Sector Sponsored Training in West Germany. Journal of the European Economic Association, forthcoming.

Lechner, M, Miquel R, Wunsch C (2007) The Curse and Blessing of Training the Unemployed in a Changing Economy: The Case of East Germany After Unification. German Economic Review 8: 468507.

Lechner, M, Wunsch C (2006) Active Labor Market Policy in East Germany: Waiting for the Economy to Take off. Working Paper, University of St. Gallen.

Lutz, H, Mahringer H, Pöschl A (2005) Schwerpunkt 1: Verhinderung und Bekämpfung der Langzeitsarbeitslosigkeit und der Jugendarbeitslosigkeit. WIFO, IHS, L\&R: Evaluierung Europäischer Sozialfonds 2000-2006, Ziel 3: Österreich. Wien.

Puhani, P (1999) Evaluating Active Labor Market Policies - Empirical Evidence for Poland during Transition, ZEW Economic Studies 5, Heidelberg: Physica.

Richardson, K, van den Berg G (2001) The Effect of Vocational Employment Training on the Individual Transition Rate from Unemployment to Work. Swedish Economic Policy Review 8: 175213.

Rosenbaum, P, Rubin D (1983) The Central Role of the Propensity Score in Observational Studies for Causal Effects. Biometrica 70: 41-55.

Rubin, D (1974) Estimating Causal Effects of Treatments in Randomized and Nonrandomized Studies. Journal of Educational Psychology 66: 668-701.

Rubin, D (1979) Using Multivariate Matched Sampling and Regression Adjustment to Control Bias in Observational Studies. Journal of the American Statistical Association 74: 318-328.

Sianesi, B (2008) Differential Effects of Swedish Active Labor Market Programmes for Unemplayed. Labour Economics 15: 370-399. 
Van Ours, J (2004) The Locking-in Effect of Subsidized Jobs. Journal of Comparative Economics 32: 37-52.

Winter-Ebmer, R, Zweimüller J (1996) Manpower Training Programmes and Employment Stability. Economica 63: 113-130. 


\section{Appendix: Matching protocol}

The results presented contain the binary comparison of each particular program to the state of non-participation for the participants in that particular program. Table 5 shows the matching estimator that is used for each such comparison.

- Table 5 about here 


\section{Tables}

Table 1: Expenditures and number of participants by program type

\begin{tabular}{|c|c|c|c|c|c|c|c|c|c|c|}
\hline & $\begin{array}{l}\text { Partici- } \\
\text { pation }\end{array}$ & $\begin{array}{l}\text { Expen- } \\
\text { ditures }\end{array}$ & $\begin{array}{l}\text { Exp. I } \\
\text { part. }\end{array}$ & $\begin{array}{l}\text { Partici- } \\
\text { pation }\end{array}$ & $\begin{array}{l}\text { Expen- } \\
\text { ditures }\end{array}$ & $\begin{array}{c:}\text { Exp. / } \\
\text { part. }\end{array}$ & $\begin{array}{l}\text { Partici- } \\
\text { pation }\end{array}$ & $\begin{array}{l}\text { Expen- } \\
\text { ditures } \\
\end{array}$ & $\begin{array}{l}\text { Exp. I } \\
\text { part. }\end{array}$ & $\begin{array}{c}\text { Exp. } \\
\text { per day }\end{array}$ \\
\hline Program & & 2000 & & & 2001 & 1 & \multicolumn{4}{|c|}{2002} \\
\hline Socio-economic enterprises & 3.400 & 31 & 9.265 & 5.700 & 39 & $6.807 !$ & 5.800 & 49 & 8.362 & 56 \\
\hline Non-profit sector projects & 2.900 & 33 & 11.448 & 3.600 & 33 & $9.056 i$ & 3.800 & 36 & 9.500 & 59 \\
\hline Orientation measures & 8.000 & 28 & 3.511 & 11.800 & 29 & $2.451 !$ & 18.200 & 28 & 1.535 & 19 \\
\hline Job coaching & 1.700 & 10 & 5.915 & 2.700 & 11 & $4.180 i$ & 4.100 & 10 & 2.447 & 18 \\
\hline Active job search & 22.600 & 41 & 1.788 & 35.000 & 37 & 1.063 & 46.200 & 41 & 892 & 21 \\
\hline Qualification measures & 77.700 & 110 & 1.411 & 65.600 & 104 & 1.591 & 54.400 & 123 & 2.262 & 29 \\
\hline Course subsidies & 17.200 & 11 & 622 & 26.900 & 19 & 710 & 33.100 & 23 & 695 & 14 \\
\hline Business start-up program & 11.900 & 31 & 2.613 & 22.300 & 32 & $1.448 !$ & 34.300 & 34 & 980 & 8 \\
\hline $\begin{array}{l}\text { Qualification programs for } \\
\text { employees }\end{array}$ & 7.600 & 18 & 2.316 & 27.200 & 28 & 1.044 & 44.300 & 35 & 763 & 17 \\
\hline Beneficence for labor & 3.400 & 8 & 2.412 & 3.600 & 5 & $1.472 !$ & 4.400 & 4 & 909 & 4 \\
\hline Integration subsidies & 16.100 & 105 & 6.522 & 18.300 & 97 & $5.301 !$ & 18.000 & 69 & 3.839 & 26 \\
\hline
\end{tabular}

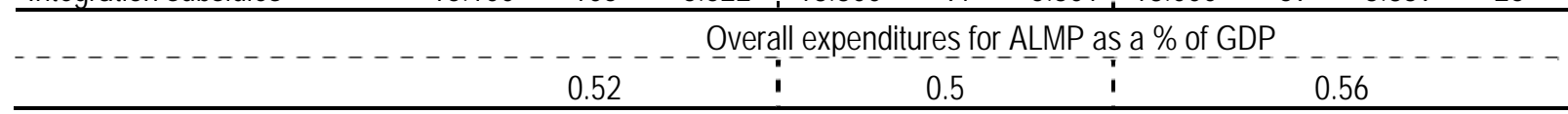

Note: $\quad$ Expenditures in million Euros. Expenditures per participation and per day are in Euros. The numbers in the column 'participation' denote cases not persons (multiple participations occur frequently). Sources:

Basisinformationsbericht Österreich (2004), AMS Data Warehouse, OECD source data base. 
Table 2: Selection of the population used in the estimation

\begin{tabular}{|c|c|c|c|c|c|c|}
\hline $\begin{array}{l}\text { Nonpartici- } \\
\text { pation }\end{array}$ & $\begin{array}{l}\text { Socio-econo- } \\
\text { mic enterprises }\end{array}$ & $\begin{array}{c}\text { Non-profit } \\
\text { sector projects }\end{array}$ & $\begin{array}{l}\text { Active job } \\
\text { search }\end{array}$ & Job coaching & $\begin{array}{c}\text { Qualification } \\
\text { measures }\end{array}$ & $\begin{array}{l}\text { Course } \\
\text { subsidies }\end{array}$ \\
\hline \multicolumn{7}{|c|}{ All persons who switch into unemployment for the first time between 2000 and 2002} \\
\hline 706653 & 2119 & 1474 & 36870 & 1152 & 31277 & 17489 \\
\hline \multicolumn{7}{|c|}{ Simulated start date before the end of 2002 and in 'defining unemployment spell' } \\
\hline $289^{\prime} 629$ & 2119 & 1474 & $366^{\prime} 870^{-}$ & $1 ' 152$ & 31277 & $177^{\prime} 489$ \\
\hline \multicolumn{7}{|c|}{ No temporary layoffs* } \\
\hline 221729 & 2014 & 1382 & 351312 & $1 ' 071$ & $29 ' 518$ & $15^{\prime} 922$ \\
\hline \multicolumn{7}{|c|}{ Age at entry between 25 and 50} \\
\hline 119925 & 979 & 894 & 22452 & 613 & 20704 & 11447 \\
\hline \multicolumn{7}{|c|}{ Duration of last employment $>2$ months } \\
\hline 105342 & 693 & 650 & 19316 & 453 & $18^{\prime} 233$ & $10^{\prime} 150$ \\
\hline
\end{tabular}

Note: * Only sample without a fixed future re-employment date (information provided by the caseworker). 
Table 3: Mean characteristics of selected variables (mean or share in \%)

\begin{tabular}{|c|c|c|c|c|c|c|c|}
\hline Variable & $\begin{array}{l}\text { Non- } \\
\text { partici- } \\
\text { pation }\end{array}$ & $\begin{array}{l}\text { Socio- } \\
\text { econ. } \\
\text { enter- } \\
\text { prises }\end{array}$ & $\begin{array}{c}\text { Non- } \\
\text { profit } \\
\text { sector } \\
\text { projects }\end{array}$ & $\begin{array}{c}\text { Active } \\
\text { job } \\
\text { search }\end{array}$ & $\begin{array}{l}\text { Job } \\
\text { coaching }\end{array}$ & $\begin{array}{c}\text { Quali- } \\
\text { fication } \\
\text { measure }\end{array}$ & $\begin{array}{l}\text { Course } \\
\text { subsidies }\end{array}$ \\
\hline Number of observations & 105342 & 693 & 650 & 19316 & 453 & 18233 & 10150 \\
\hline \multicolumn{8}{|l|}{ Personal characteristics (in \%) } \\
\hline Female & 51 & 49 & 54 & 50 & 54 & 62 & 55 \\
\hline Disabled & 5 & 21 & 22 & 7 & 22 & 10 & 10 \\
\hline Foreigner & 20 & 12 & 7 & 21 & 11 & 13 & 14 \\
\hline Age at (hypothetical) program entry & 36 & 40 & 37 & 37 & 37 & 37 & 37 \\
\hline Desires vocational change & 18 & 26 & 21 & 29 & 23 & 22 & 20 \\
\hline $\begin{array}{l}\text { Pregnant at the (hypothetical) program start } \\
\text { (only women subsample) } \\
\text { Average month of pregnancy }\end{array}$ & 2.5 & 0 & 1.7 & 0.3 & 0.4 & 0.5 & 0.5 \\
\hline (only women subsample with pregnancy)* & 5.4 & 0 & 3.6 & 3.7 & 3.5 & 3.6 & 3.6 \\
\hline \multicolumn{8}{|l|}{ Education (in \%) } \\
\hline No formal education & 3 & 3 & 4 & 6 & 4 & 2 & 3 \\
\hline Compulsory school & 34 & 50 & 40 & 35 & 46 & 28 & 26 \\
\hline Apprenticeship & 35 & 32 & 29 & 30 & 27 & 37 & 35 \\
\hline Schooling degree with vocational & & & & & & & 0 \\
\hline $\begin{array}{l}\text { qualification } \\
\text { Schooling degree with university }\end{array}$ & 6 & 5 & 7 & 6 & 8 & 10 & 9 \\
\hline entrance qualification & 9 & 4 & 7 & 11 & 4 & 12 & 12 \\
\hline Academic degree & 5 & .9 & 9 & 5 & 4 & 4 & 7 \\
\hline Education missing & 8 & 4 & 4 & 8 & 6 & 8 & 8 \\
\hline \multicolumn{8}{|l|}{ Income (in EUR / day) } \\
\hline $\begin{array}{l}\text { Last earnings } \\
\end{array}$ & 42 & 38 & 34 & 45 & 37 & 43 & 43 \\
\hline $\begin{array}{l}\text { Unemployment insurance benefit } \\
\text { claim at (hypothetical) program entry }\end{array}$ & 22 & 10 & 10 & 17 & 11 & 19 & 19 \\
\hline \multicolumn{8}{|l|}{ Last employment (in months) } \\
\hline Duration of last employment & 28 & 20 & 20 & 28 & 23 & 32 & 33 \\
\hline \multicolumn{8}{|l|}{ Fractions of entire period in data (in \%) } \\
\hline Fraction of unemployment & 12 & 22 & 21 & 14 & 18 & 12 & 11 \\
\hline Fraction of employment & 68 & 59 & 53 & 67 & 60 & 67 & 68 \\
\hline Fraction of remaining time & 20 & 19 & 27 & 19 & 22 & 21 & 22 \\
\hline \multicolumn{8}{|l|}{ Mean duration (in months) } \\
\hline Employment over 5 years before & 21 & 16 & 14 & 21 & 17 & 24 & 25 \\
\hline Out of labor force over $5 \mathrm{y}$. before & 1.5 & 1.5 & 1.8 & 1.3 & 1.6 & 1.4 & 1.5 \\
\hline Parental leave over 5 y. before & 2.1 & 1.6 & 2.6 & 2.0 & 2.0 & 2.6 & 2.1 \\
\hline \multicolumn{8}{|l|}{ Program history (in \%) } \\
\hline $\begin{array}{l}\text { Last program of the same kind } \\
\end{array}$ & -- & 23 & 17 & 17 & 14 & 15 & 14 \\
\hline \multicolumn{8}{|l|}{ Information on current unemployment spell } \\
\hline Entry $1^{\text {st }}$ quarter of the year (in \%) & 27 & 32 & 44 & 31 & 29 & 29 & 28 \\
\hline $2^{\text {nd }}$ quarter (in \%) & 23 & 24 & 20 & 26 & 20 & 24 & 23 \\
\hline $3^{\text {rd }}$ quarter (in \%) & 23 & 22 & 23 & 25 & 26 & 25 & 26 \\
\hline $4^{\text {th }}$ quarter (in \%) & 28 & 22 & 13 & 19 & 25 & 22 & 24 \\
\hline Time in unemployment before (hypothetical) & & & & & & & \\
\hline program entry (in months) & 3.1 & 7.8 & 6.3 & 5.7 & 7.5 & 4.9 & 4.9 \\
\hline \multicolumn{8}{|l|}{ a information (in \%) } \\
\hline UE rate 2000 & 7.0 & 6.7 & 6.9 & 8.5 & 6.2 & 7.2 & 6.7 \\
\hline Local fraction unemployment & & & & & & & \\
\hline assistance recipients 2001 & 32 & 32 & 32 & 44 & 28 & 35 & 32 \\
\hline Local fraction of long-term & & & & & & & \\
\hline unemployed 2000 & 20 & 19 & 20 & 29 & 15 & 22 & 19 \\
\hline Residence in the state of Vienna & 23 & 17 & 5 & 65 & 7 & 30 & 23 \\
\hline \multicolumn{8}{|l|}{ Employment after begin of program (in \%; outcome) } \\
\hline Employed 1 year after begin & 62 & 37 & 41 & 53 & 37 & 51 & 59 \\
\hline Employed 2 years after begin & 64 & 45 & 50 & 58 & 47 & 62 & 68 \\
\hline Employed 3 years after begin & 64 & 49 & 54 & 59 & 53 & 66 & 70 \\
\hline
\end{tabular}

Note: If not stated otherwise, we compute all variables of the employment history at the entry into the defining unemployment spell. (*) Pregnancy is the only variable that is computed on the women's subsample. 
Table 4: Results of the propensity score estimation

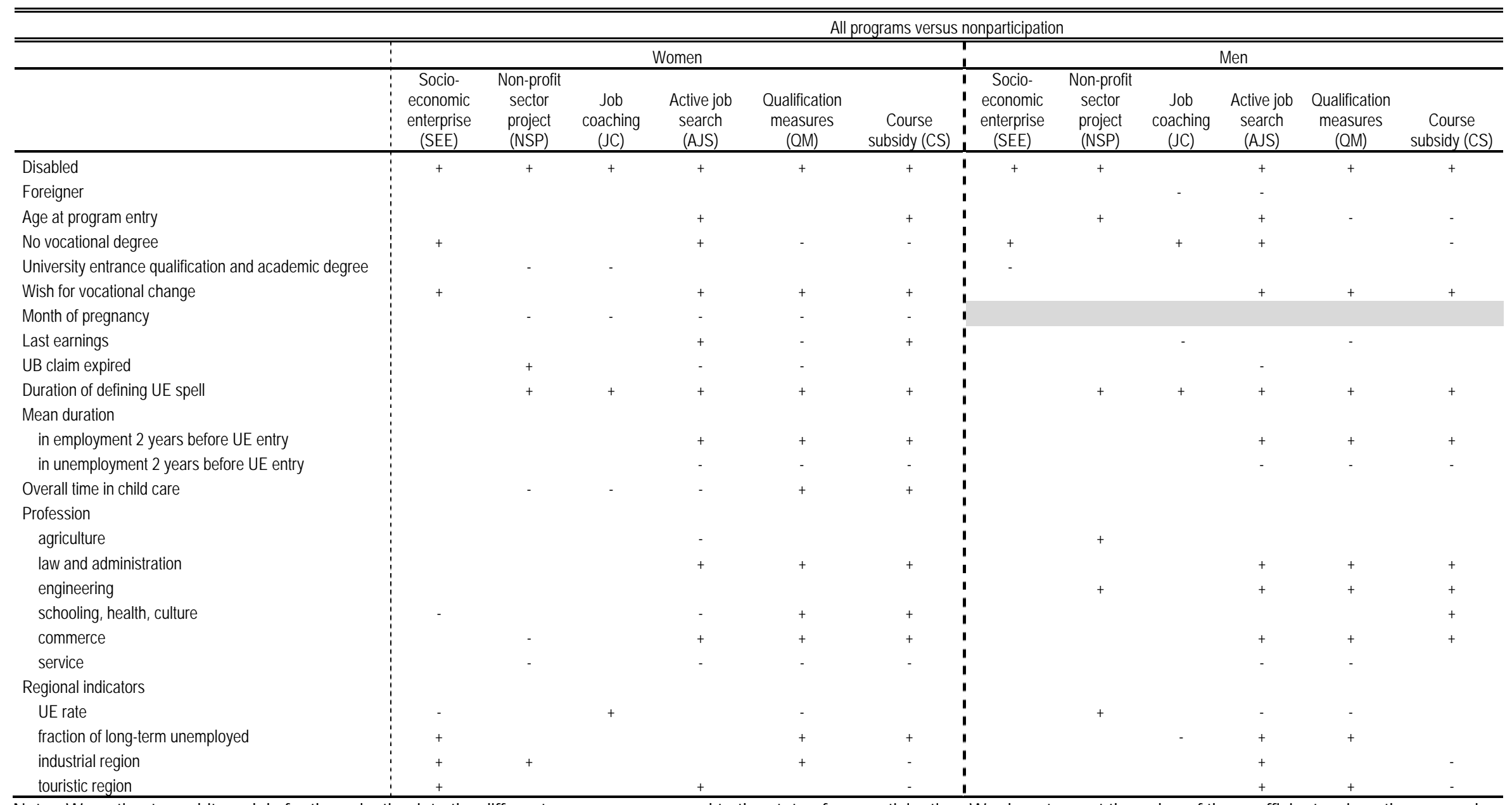

Note: We estimate probit models for the selection into the different programs compared to the state of nonparticipation. We do not report the value of the coefficients, since they are only identified up to scale and thus not comparable between the different models. + (-) denotes that the respective variable has a positive (negative) influence on the participation probability that is significant on the $5 \%$ level. Reading example 1: For the selection of women into job coaching (JC) compared to non-participation, we find a positive influence of the disability status on the probability of participating in JC. Reading example 2: For the selection of men into active job search (AJS) compared to non-participation, we find that the wish for a vocational change increases the probability of participating in AJS. 
Step 1 Estimate a probit model to obtain the choice probabilities: $\hat{p}_{i}=\operatorname{Pr}\left(D=1 \mid X=X_{i}\right)$

Step 2 Restrict sample to common support: Delete all $\mathrm{D}=1$ observations with $\hat{p}_{i}$ larger than the largest estimated propensity score among the $\mathrm{D}=0$ observations.

Step 3 Estimate the counterfactual expectation of the outcome variable $E\left[Y^{0} \mid D=1\right]$

Standard propensity score matching step (binary treatment)

a-1) Choose one observation from the $D=1$ subsample and delete it from that pool.

b-1) Find an observation from the $D=0$ subsample that is as close as possible to the one chosen in step a-1) in terms of $[\hat{P}(x), \tilde{x}]$, with respect to the Mahalanobis distance. Do not remove that observation, so that it can be used again.

c-1) Repeat a-1) and b-1) until no participant in $D=1$ is left.

\section{Exploit thick support of $X$ to increase efficiency (radius matching step)}

$\mathrm{d}-1$ ) Compute the maximum distance $(\delta)$ obtained for any comparison between treated and matched comparison observations.

a-2) Repeat a-1).

b-2) Repeat b-1). If possible, find other observations of the $D=0$ subsample that are at least as close as $R \times \delta$ to the one chosen in step a-2); $R$ is fixed to $90 \%$ in this application but different values are examined in the sensitivity analysis. Do not remove these observations, so that they can be used again. Compute weights for all chosen comparisons observations such that these weights are proportional to their distance (calculated in b-1). Normalise the weights such that they add to one.

$c-2$ ) Repeat a-2) and b-2) until no participant in $D=1$ is left.

$\mathrm{d}-2$ ) For every $D=0$ observation, add the weights obtained in b-2).

\section{Exploit double robustness property to adjust small mismatches by regression}

e) Using the weights $w\left(x_{i}\right)$ obtained in $\mathrm{d}-2$ ), run a weighted linear regression of the outcome variable on the variables used to define the distance (and an intercept).

$\mathrm{f}-1)$ Predict the potential outcome $y^{0}\left(x_{i}\right)$ of every observation in $D=0$ and $D=1$ using the coefficients of this regression: $\hat{y}^{0}\left(x_{i}\right)$.

$\mathrm{f}$-2) Estimate the bias of the matching estimator for $E\left[Y^{0} \mid D=1\right]$ as:

$$
\frac{1}{N^{1}} \sum_{i=1}^{N} \underline{1}\left(D_{i}=1\right) \hat{y}^{0}\left(x_{i}\right)-\sum_{i=1}^{N} \underline{1}\left(D_{i}=0\right) w\left(x_{i}\right) \hat{y}^{0}\left(x_{i}\right) .
$$

g) Using the weights obtained by weighted matching in d-2), compute a weighted mean of the outcome variables in $D=0$. Subtract the bias from this estimate.

\section{Final estimate}

h) Compute the treatment effect by subtracting the weighted mean of the outcomes in the comparison group ( $D=$ 0) from the mean in the treatment group $(D=1)$.

Note: $\quad$ The table refers to the estimation of ATET. The modifications for ATEN are obvious. $\tilde{X}$ is included to ensure a high match quality with respect to critical variables. 


\section{Figures}

Figure 1: Construction of the pregnancy start date

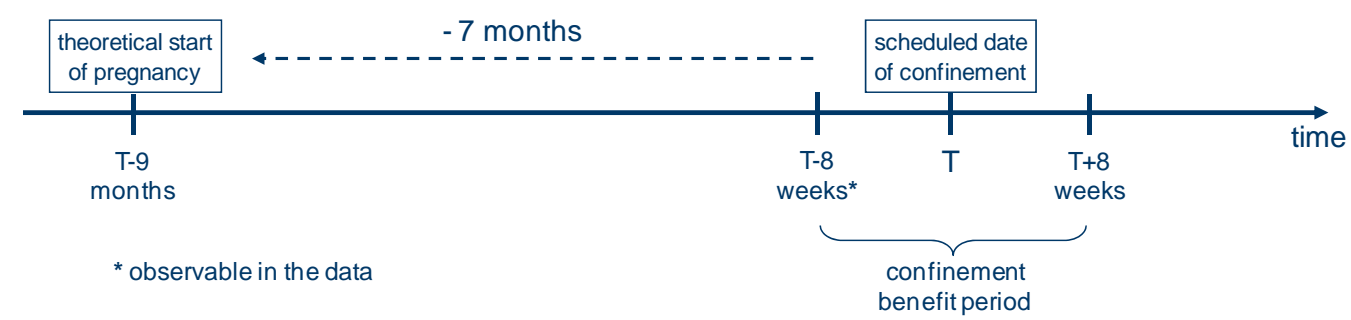


Figure 2: Employment 3 years before and after program entry
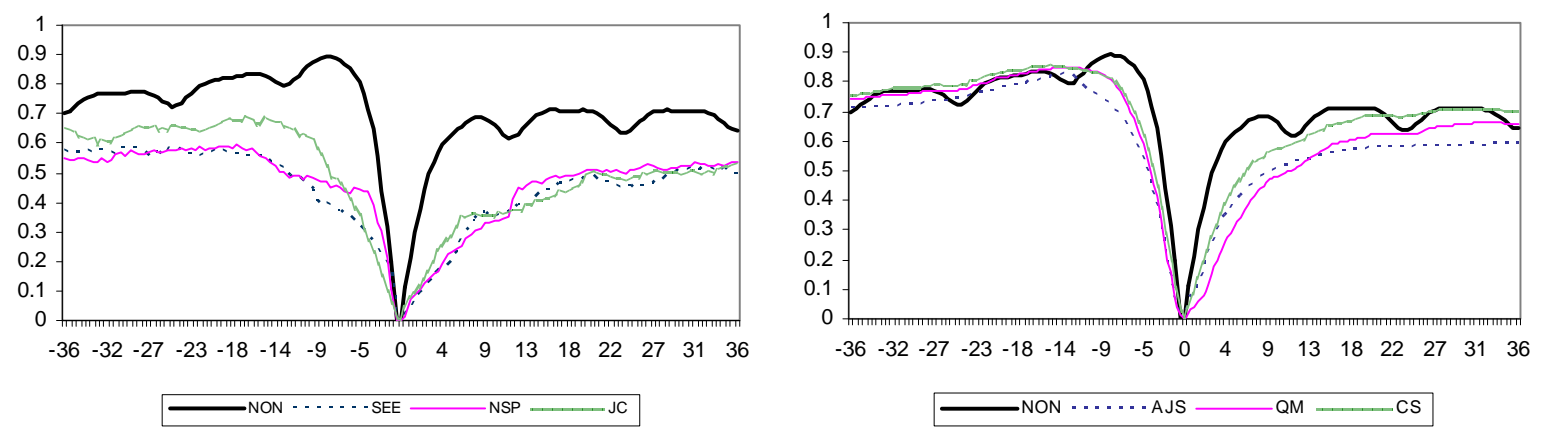

Note: $\quad$ NON: nonparticipation; SEE: socio-economic enterprises; NSP: non-profit sector projects; JC: job coaching; AJS: active job search; QM: qualification measure; CS: course subsidy. 
Figure 3: Effects of program participation versus non-participation: Employment in \%-points

Men
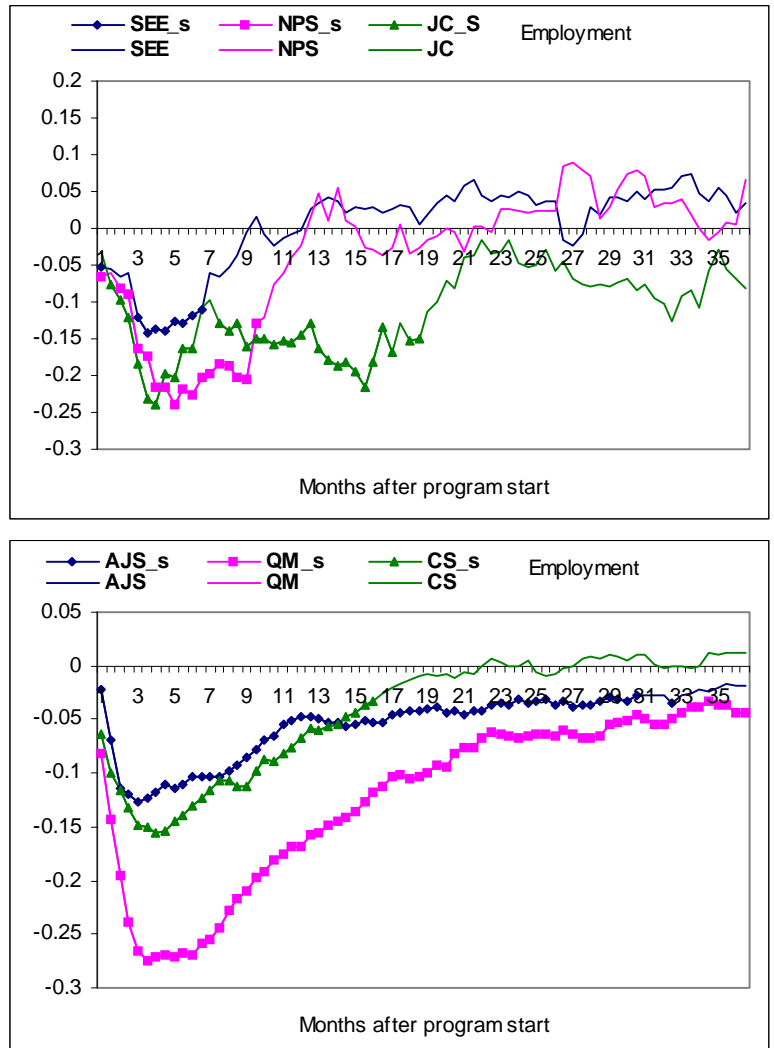

Women
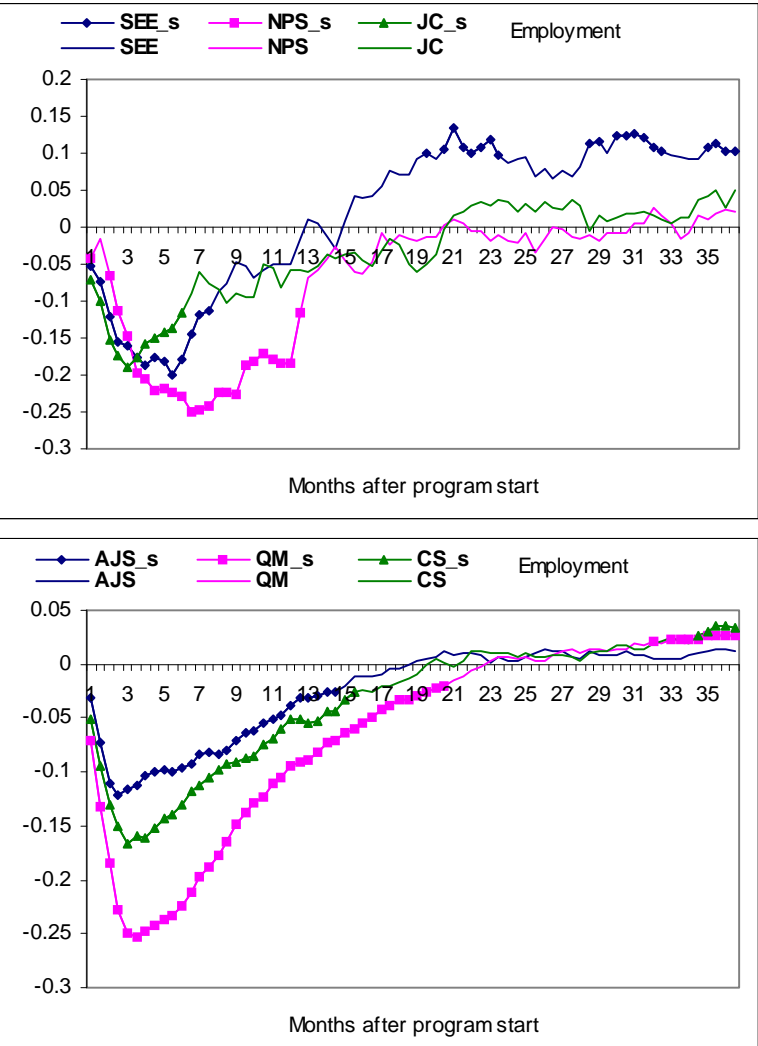

Note: Results based on matching estimation. Abscissa: Months after program entry. Ordinate: Difference of employment rates. Symbols indicate that the effect is statistically different from zero at the 95\% level. SEE: socio-economic enterprise, NSP: non-profit sector project, JC: job coaching, AJS: active job search, QM: qualification measure, CS: course subsidy. Participants (male/female): SEE (343/340), NSP (300/347), JC (206/243), AJS (9641/9638), QM (6869/11330), CS (4549/5587). 
Figure 4: Effects of program participation versus non-participation: OLF (not employed \& not

registered as unemployed) in \%-points
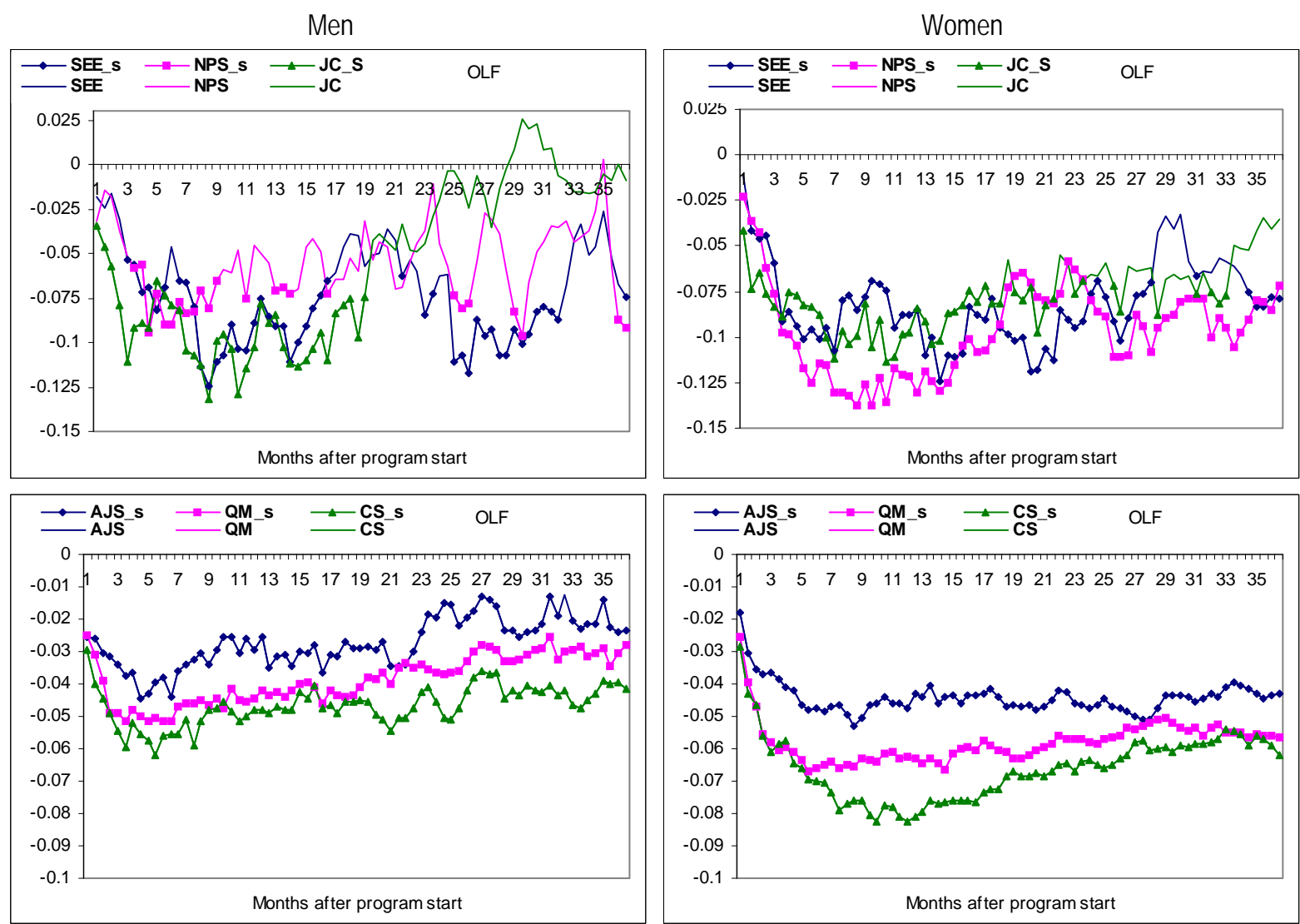

Note: Results based on matching estimation. Abscissa: Months after program entry. Ordinate: Difference of out-of the labor-force rates. Symbols indicate that the effect is statistically different from zero at the 95\% level. SEE: socioeconomic enterprise, NSP: non-profit sector project, JC: job coaching, AJS: active job search, QM: qualification measure, CS: course subsidy. Participants (male/female): SEE (343/340), NSP (300/347), JC (206/243), AJS (9641/9638), QM (6869/11330), CS (4549/5587). 
Figure 5: Effects of program participation versus non-participation: Parental leave \& pregnancy
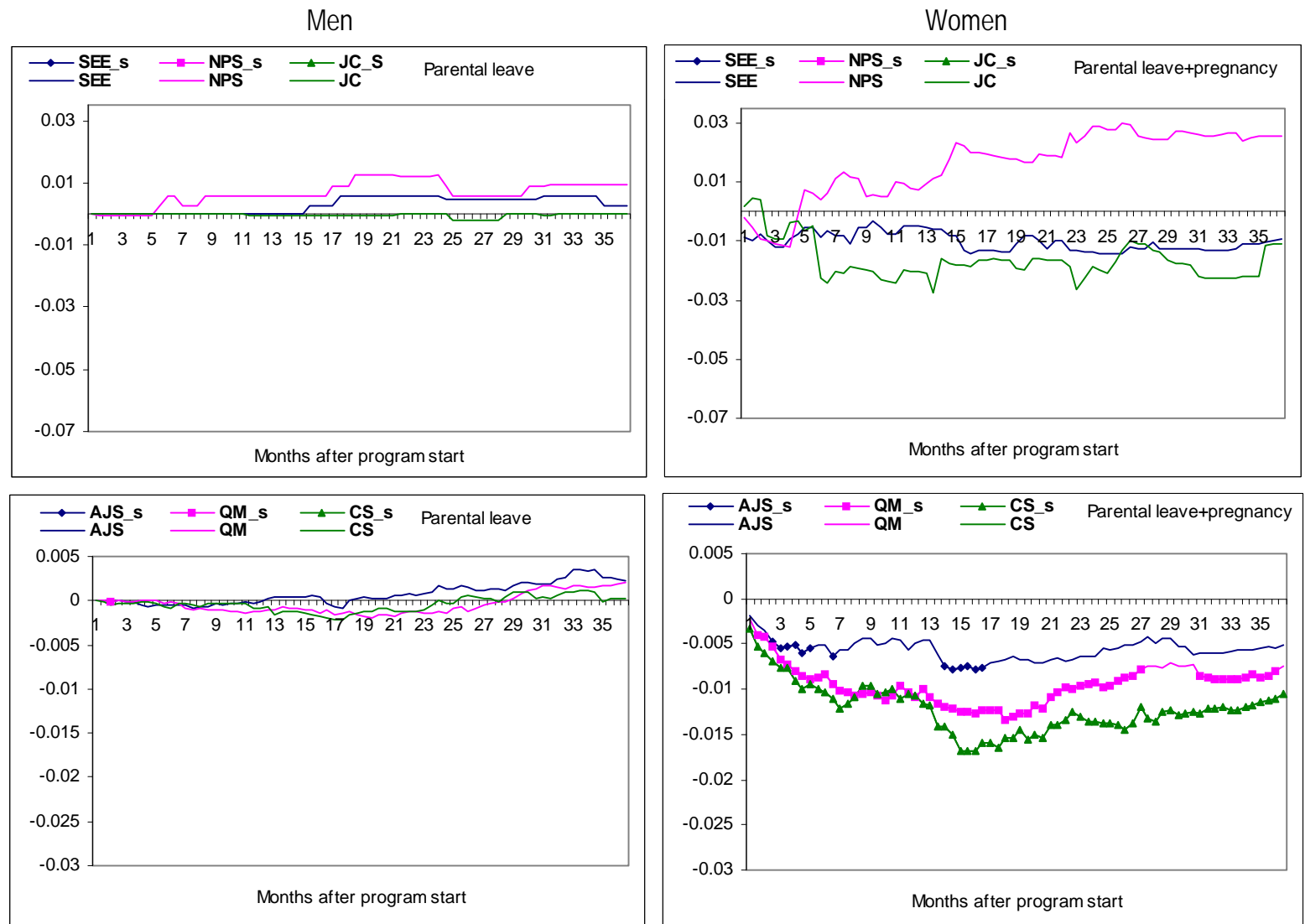

Note: $\quad$ Results based on matching estimation. Abscissa: Months after program entry. Ordinate: Difference of shares in parental leave or pregnancy. Symbols indicate that the effect is statistically different from zero at the $95 \%$ level. SEE: socio-economic enterprise, NSP: non-profit sector project, JC: job coaching, AJS: active job search, QM: qualification measure, CS: course subsidy. Participants (male/female): SEE (343/340), NSP (300/347), JC (206/243), AJS (9641/9638), QM (6869/11330), CS (4549/5587). 
Figure 6: Effects of program participation versus non-participation: Employment \& pregnancy \& parental leave
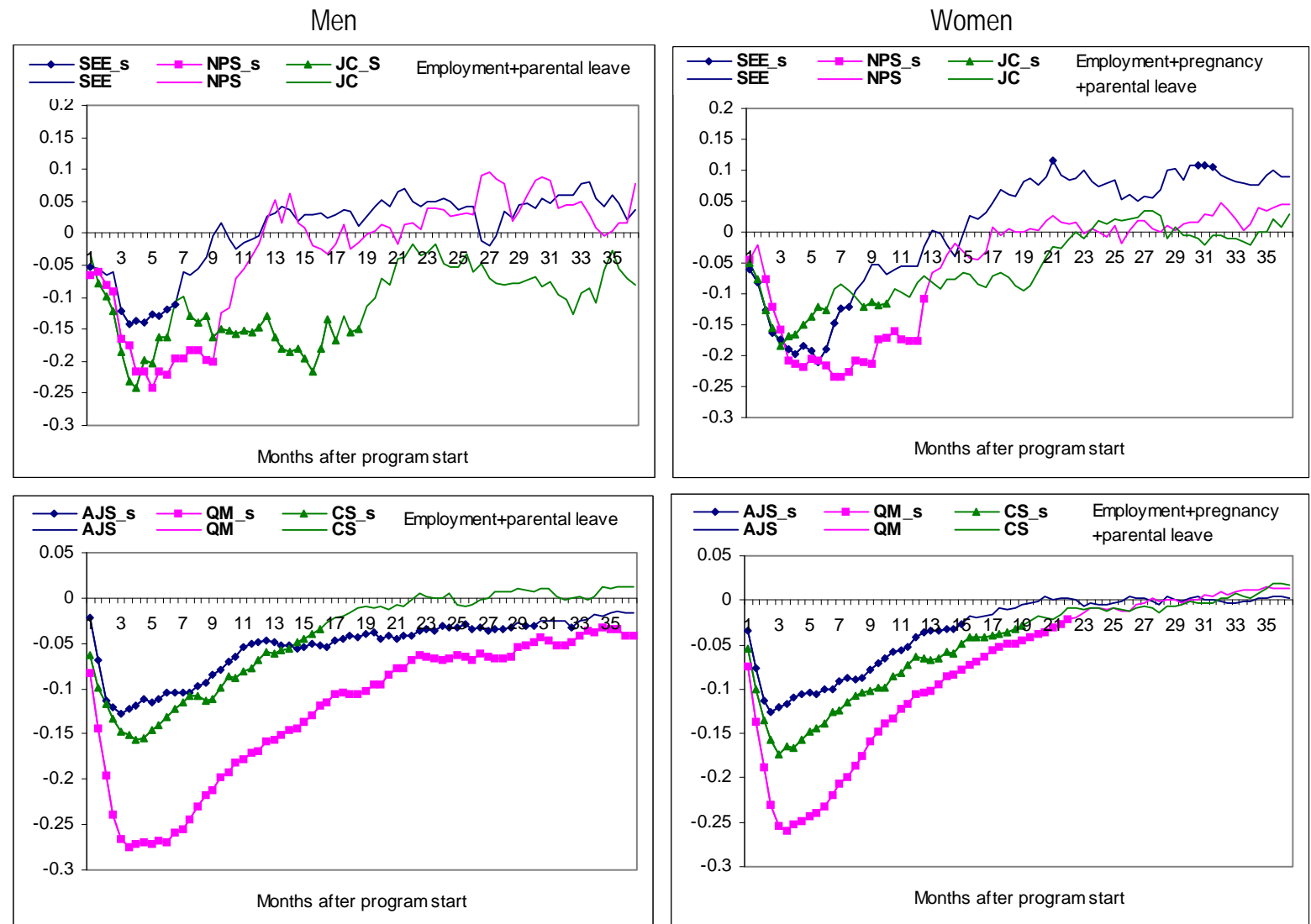

Note: Results based on matching estimation. Abscissa: Months after program entry. Ordinate: Difference of employment rates. Symbols indicate that the effect is statistically different from zero at the 95\% level. SEE: socio-economic enterprise, NSP: non-profit sector project, JC: job coaching, AJS: active job search, QM: qualification measure, CS: course subsidy. Participants (male/female): SEE (343/340), NSP (300/347), JC (206/243), AJS (9641/9638), QM (6869/11330), CS (4549/5587). 
Figure 7: Percentage of pregnant women by program status and age group

non-participants

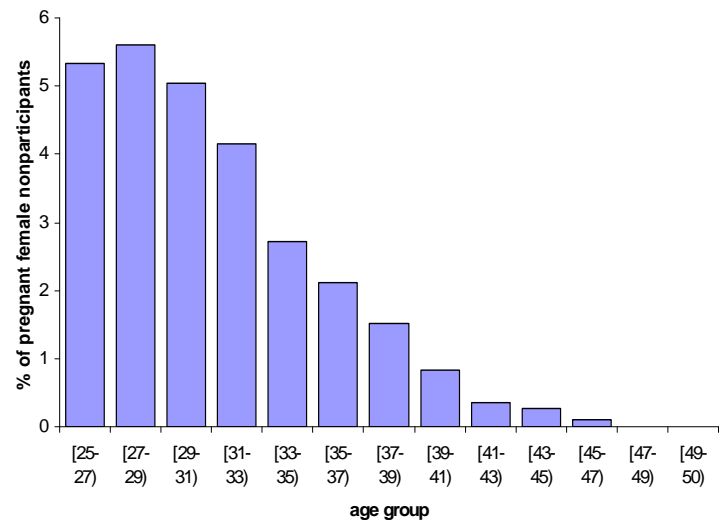

participants

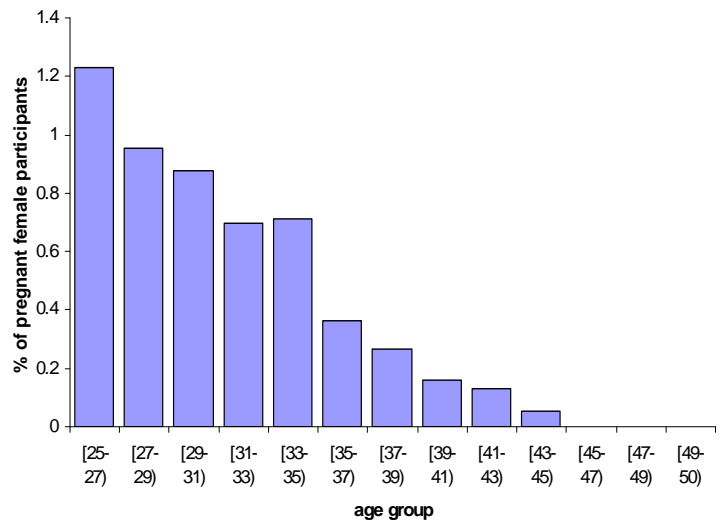

Note: The pregnancy status is computed right before the (hypothetical) program start. For this illustration we pooled all program categories due to the small fraction of pregnant women per program type. 
Figure 8: Effects of program participation versus non-participation: Women per age group
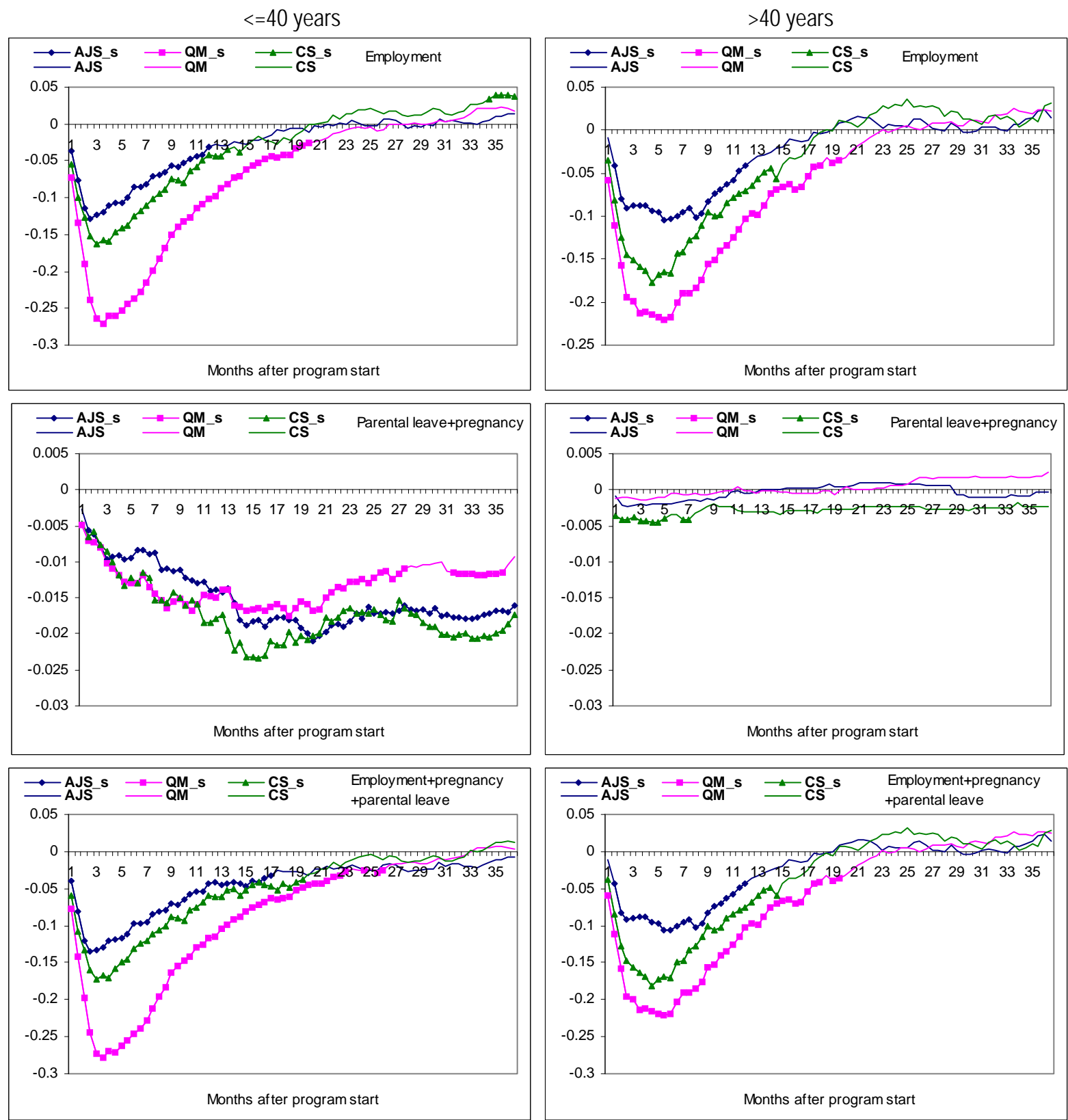

Note: Results based on matching estimation. Abscissa: Months after program entry. Ordinate: Difference of employment rates. Symbols indicate that the effect is statistically different from zero at the $95 \%$ level. AJS: active job search, QM: qualification measure, CS: course subsidy. Participants (<=40/>40): AJS (6163/3493), QM (7569/3762), CS (3672/1917). 
Figure 9: Effects of program participation versus non-participation: Employment in \%-points
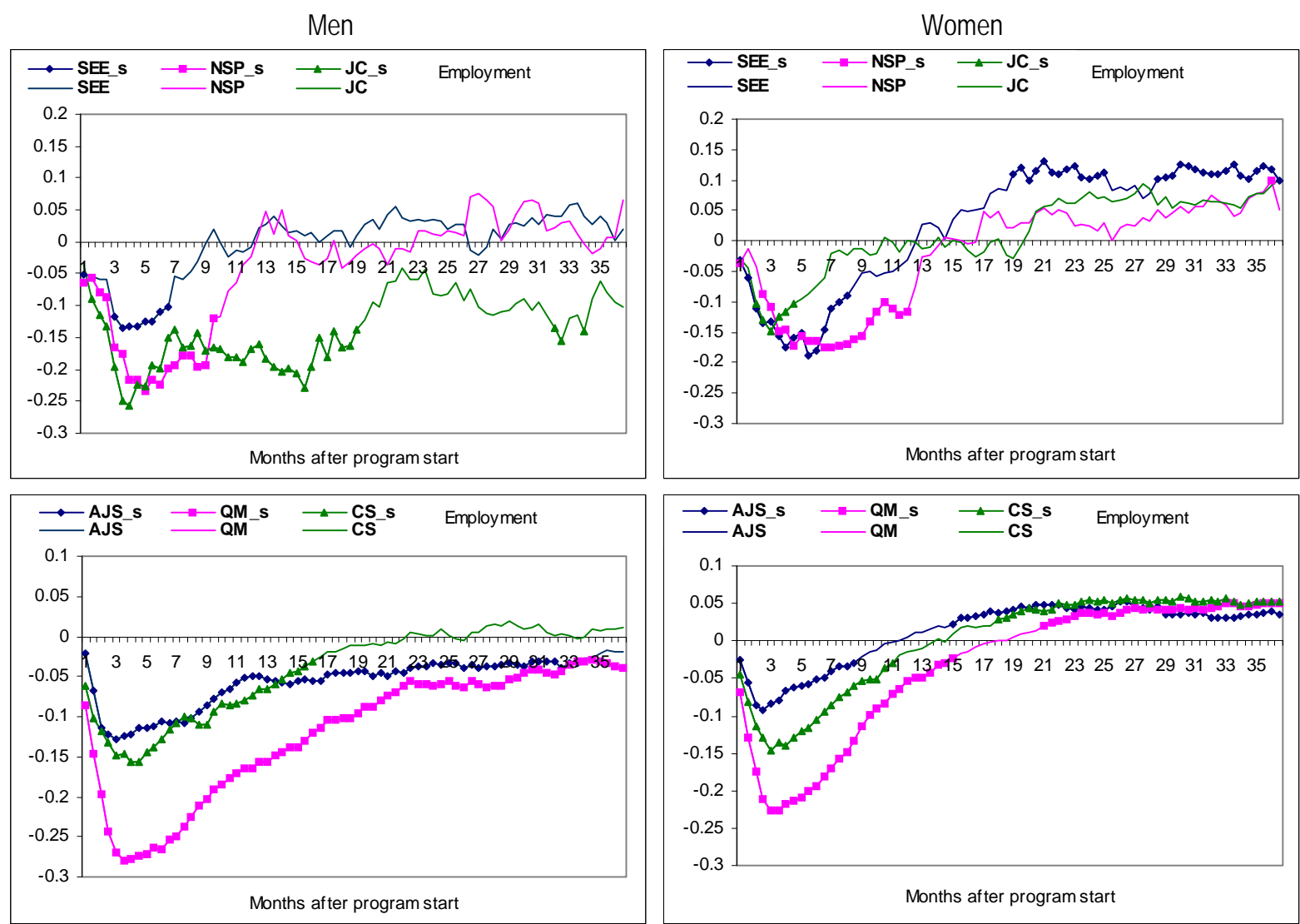

Note: Results based on matching estimation. Abscissa: Months after program entry. Ordinate: Difference of employment rates. Symbols indicate that the effect is statistically different from zero at the 95\% level. SEE: socio-economic enterprise, NSP: non-profit sector project, JC: job coaching, AJS: active job search, QM: qualification measure, CS: course subsidy. Participants (male/female): SEE (343/340), NSP (300/347), JC (206/243), AJS (9642/9640), QM (6869/11332), CS (4552/5594). 


\section{Endnotes}

$1 \quad$ For job creation schemes in Switzerland see Gerfin and Lechner (2002). Similar results appear in Lechner and Wunsch (2006) and in Caliendo, Hujer, and Thomson (2004, 2006, 2008) for Germany. For wage or integration subsidies in Sweden see Sianesi (2008) and Forslund, Johannson, and Lindqvist (2004) and for Switzerland in Lalive, van Ours, and Zweimüller (2008) and Gerfin, Lechner, and Steiger (2005). For business start-up programs in Sweden, we refer to Carling and Gustafson (1999). For training measures, comprising formal qualification, further training of any kind, and retraining see Richardson and van den Berg (2001) and Carling and Richardson (2004) for Sweden, and Gerfin and Lechner (2002) and Hujer, Thomsen, and Zeiss (2005) for Switzerland and Germany. Lechner, Miquel, and Wunsch (2004) investigate long-run effects for Germany. Winter-Ebmer and Zweimüller (1996), Hofer and Weber (2004a, b), and Lutz, Mahringer, and Pöschl (2005) investigate employment effects for different instruments of the Austrian ALMP.

2 Bergemann and van den Berg (2006) classify countries to have a low female labor force participation rate if it is at least 10 percent lower than the male labor force participation rate.

3 The UB claim, for instance, for a 40 year old unemployed person, who paid UI contributions for 312 weeks in the last 120 months, is 39 weeks. See the internet appendix for a summary table of the various exceptions.

$4 \quad$ Unemployed receive a fixed quota of currently 7.42 Euros a day. Multiple births prolong the period after confinement to 12 weeks.

5 The default entitlement period was 549 days, which could be prolonged between July 2001 and December 2002 to provide a gradual adjustment to the childcare benefit regulations.

6 If the parents share child care times, the maximum entitlement period is prolonged to 36 months. If they fail to prove regular medical consultations, childcare benefits are reduces to 7.27 Euros per day. Extra earnings are allowed up to a maximum of 14.600 Euros per year without leading to a reduction in benefits.

$7 \quad$ In case of a business foundation, future workers are trained with specific skills for the new firm. In case of a firm closure the dismissed are trained to adjust their skills for further employment in a new firm.

$8 \quad$ For business start-up programs (BSU), qualification for employees (QFE), and integration subsidies (IS) we find decreasing costs per participation over time. BSU are less frequently accompanied by other courses. QFE measures are more and more redesigned into smaller specialized measures. The refund rate of IS, granted to the employers, decreases over time.

$9 \quad$ All variables that can potentially be used to further distinguish the wide range of qualification measures have bad filling degrees.

10 Childcare in general is universally available. Our remaining conditioning variables in the propensity score capture their determinants, so that there is no problem for the validity of the CIA.

11 The local labor market data was provided by the Austrian Institute of Economic Research and is merged to the individual unemployed via regional identifiers of the local Public Employment Service office.

12 As in Lechner, Miquel, and Wunsch (2004, 2005).

13 Denote this unemployment spell as the 'defining UE spell'.

14 The entire set of variables that are used in the estimation part of this paper is available from the internet appendix. It covers personal characteristics, like family status, education, last profession, last industry sector, last firm size, last salary, remaining benefit duration at program entry, different aspects of the labor market history, and times of child care, program history and a set of regional indicators.

15 The estimation results for all different comparisons can be found in the internet appendix.

16 The outcome variable is also listed in the top line of every panel.

$17 \quad$ Note that we additionally deleted all individuals who received financial support right before the

(hypothetical) entry into the program which had only marginal impact on the population size. See the internet appendix for details.

${ }_{18}$ Note that it is possible to estimate fairly small effects (below $5 \%$-points) due to the larger number of participants in the programs collected in group two. Such small effects could not be identified non-parametrically before since comparable studies usually rely on (smaller) samples instead of using the population as is done here. 19 Taking unemployment as the outcome variable, it can be seen for male participants that none of the programs decreases unemployment. Qualification measures even increase unemployment by 4 percent. For women only qualification measures and course subsidies decrease unemployment, but only by 1.5 to 2.5 percent. For further details see the internet appendix.

20 Women receive financial support eight weeks before a scheduled confinement and for up to 3 years afterwards, as described in Section 2. Since part of this period is counted as contribution times to the pension schemes, we observe them in the social security records.

$21 \quad$ The respective graphs can be found in the internet appendix. 
22 In this sense our study reaffirms the conclusion by Bergemann and van den Berg (2006) that the program effects for women may be larger because of their additional possibilities of moving in and out of nonparticipation: parental leave is a classical component of the labor market state 'out-of-the-labor force'. 


\section{KIDS OR COURSES?}

\section{GENDER DIFFERENCES IN THE EFFECTS OF ACTIVE \\ LABOR MARKET POLICIES}

\section{Internet Appendix}

Michael Lechner ${ }^{*}$ and Stephan Wiehler

Swiss Institute for Empirical Economic Research (SEW)

University of St.Gallen

Date this version has been printed: 04 March 2008

Address for correspondence: Michael Lechner, Professor of Econometrics, Swiss Institute for Empirical Economic Research (SEW), University of St. Gallen, Varnbühlstrasse 14, CH-9000 St. Gallen, Switzerland, Michael.Lechner@unisg.ch,www.siaw.unisg.ch/lechner. 


\section{Staggered unemployment benefit claims}

Table 1: UB claim as a function of contribution time and age

\begin{tabular}{|lcccc|}
\hline & $\begin{array}{c}\text { Contribution } \\
\text { time in weeks }\end{array}$ & $\begin{array}{c}\text { Prior relevant } \\
\text { time in months }\end{array}$ & $\begin{array}{c}\text { Entitlement in } \\
\text { weeks }\end{array}$ & Age restriction \\
\hline 1st application & 52 & 24 & 20 & no \\
2nd application & 28 & 12 & 20 & no \\
\hdashline prolongations & 156 & 60 & 30 & no \\
. & 312 & 120 & 39 & $>=40$ \\
. & 468 & 180 & 52 & $>=50$ \\
& 780 & 300 & 78 & $>=60$ \\
\hline
\end{tabular}

\section{Mean characteristics per program group}

Table 2: Mean Characteristics per Program Group

\begin{tabular}{|c|c|c|c|c|c|c|c|}
\hline & NON & SEE & NSP & AJS & $\mathrm{JC}$ & $\mathrm{QM}$ & CS \\
\hline Variable $\backslash N$ & 105342 & 693 & 650 & 19316 & 453 & 18233 & 10150 \\
\hline \multicolumn{8}{|c|}{ Personal Characteristics } \\
\hline Female & 50.78 & 49.49 & 53.69 & 50.02 & 53.64 & 62.18 & 55.14 \\
\hline Disabled & 5.44 & 21.21 & 22.31 & 7.09 & 21.85 & 9.87 & 9.51 \\
\hline Foreigner & 19.73 & 11.98 & 7.38 & 20.60 & 11.26 & 13.16 & 13.96 \\
\hline Age at program entry & 36.16 & 39.83 & 36.81 & 37.19 & 37.31 & 36.58 & 36.77 \\
\hline Wish for vocational change & 17.51 & 25.83 & 21.38 & 29.23 & 22.74 & 22.06 & 19.76 \\
\hline \multicolumn{8}{|c|}{ Family Status ${ }^{*}$} \\
\hline Divorced & 8.29 & 17.03 & 14.31 & 14.74 & 12.36 & 12.68 & 11.53 \\
\hline Single & 34.12 & 30.74 & 40.46 & 32.49 & 36.87 & 32.66 & 34.01 \\
\hline Married & 45.17 & 39.25 & 30.62 & 42.01 & 35.32 & 42.92 & 41.71 \\
\hline Widowed & 0.50 & 1.01 & 0.77 & 0.63 & 1.10 & 0.53 & 0.33 \\
\hline Living community & 5.83 & 5.92 & 6.77 & 4.59 & 6.84 & 5.06 & 5.40 \\
\hline Missing & 6.10 & 6.06 & 7.08 & 5.54 & 7.51 & 6.15 & 7.01 \\
\hline \multicolumn{8}{|c|}{ Education* } \\
\hline No schooling degree & 3.24 & 3.46 & 3.85 & 5.85 & 4.42 & 2.00 & 2.52 \\
\hline Compulsory schooling & 33.55 & 49.93 & 40.15 & 35.12 & 45.92 & 28.09 & 26.33 \\
\hline Apprenticeship & 35.42 & 32.18 & 28.62 & 29.68 & 27.37 & 36.50 & 35.09 \\
\hline Vocational entrance degree & 5.74 & 5.19 & 6.92 & 5.71 & 8.17 & 9.80 & 8.73 \\
\hline University entrance qualification & 9.14 & 4.33 & 7.08 & 11.44 & 4.42 & 11.59 & 11.99 \\
\hline Academic Degree & 5.03 & 0.87 & 8.92 & 4.52 & 3.97 & 4.45 & 7.21 \\
\hline Missing & 7.88 & 4.04 & 4.46 & 7.68 & 5.74 & 7.58 & 8.12 \\
\hline \multicolumn{8}{|c|}{$\mathrm{Job}^{*}$} \\
\hline Agriculture, Forestry & 1.39 & 1.59 & 2.46 & 0.91 & 2.21 & 0.70 & 0.82 \\
\hline Production & 32.80 & 46.03 & 40.31 & 31.67 & 43.05 & 25.01 & 25.10 \\
\hline Commerce & 12.80 & 11.83 & 9.69 & 15.73 & 10.82 & 15.14 & 13.60 \\
\hline Service & 17.99 & 18.04 & 11.54 & 16.17 & 12.80 & 12.36 & 12.50 \\
\hline Engineering & 3.24 & 2.02 & 1.38 & 4.75 & 1.32 & 3.69 & 4.83 \\
\hline Law and administration & 12.89 & 10.25 & 12.00 & 19.88 & 10.82 & 23.44 & 21.35 \\
\hline Health, education, culture & 6.69 & 3.46 & 11.08 & 6.38 & 4.64 & 7.26 & 9.57 \\
\hline Others & 0.17 & 0.00 & 0.31 & 0.09 & 0.00 & 0.24 & 0.20 \\
\hline Missing & 12.02 & 6.78 & 11.23 & 4.42 & 14.35 & 12.16 & 12.04 \\
\hline \multicolumn{8}{|c|}{ Last sector* } \\
\hline Primary sector & 1.10 & 1.01 & 0.77 & 0.39 & 0.88 & 0.49 & 0.51 \\
\hline Energy, water, mining & 0.50 & 0.72 & 0.31 & 0.22 & 0.66 & 0.37 & 0.55 \\
\hline Production & 15.92 & 18.61 & 15.08 & 15.48 & 21.85 & 17.56 & 16.89 \\
\hline Transport, telecommunication & 5.69 & 3.75 & 2.31 & 6.31 & 3.53 & 5.40 & 5.80 \\
\hline Construction & 12.05 & 6.49 & 4.92 & 6.62 & 7.28 & 7.22 & 6.93 \\
\hline Commerce & 19.70 & 18.90 & 14.31 & 25.49 & 20.75 & 25.74 & 22.87 \\
\hline
\end{tabular}




\begin{tabular}{|c|c|c|c|c|c|c|c|}
\hline Schooling, health, culture & 6.77 & 10.25 & 16.77 & 6.84 & 7.95 & 8.19 & 9.18 \\
\hline Tourism & 12.82 & 8.08 & 5.85 & 9.32 & 8.39 & 8.80 & 8.21 \\
\hline Banking, IT & 3.48 & 2.74 & 3.54 & 4.92 & 2.21 & 4.34 & 4.35 \\
\hline Others & 17.99 & 27.27 & 29.54 & 20.75 & 20.53 & 18.00 & 20.44 \\
\hline Household & 0.23 & 0.00 & 0.31 & 0.21 & 0.44 & 0.22 & 0.16 \\
\hline State authority & 3.75 & 2.16 & 6.31 & 3.45 & 5.52 & 3.66 & 4.11 \\
\hline Missing & 0.00 & 0.00 & 0.00 & 0.00 & 0.00 & 0.00 & 0.00 \\
\hline \multicolumn{8}{|c|}{ Size of last employer in persons* } \\
\hline$<10$ & 28.01 & 18.33 & 17.54 & 23.73 & 23.40 & 25.33 & 26.46 \\
\hline$[10,99]$ & 34.18 & 40.98 & 43.08 & 34.77 & 35.10 & 35.56 & 36.08 \\
\hline$[100,499]$ & 17.81 & 22.22 & 17.08 & 20.30 & 20.53 & 20.09 & 19.56 \\
\hline$>499$ & 11.90 & 13.13 & 12.00 & 16.43 & 17.66 & 13.59 & 12.03 \\
\hline Missing & 8.10 & 5.34 & 10.31 & 4.76 & 3.31 & 5.44 & 5.87 \\
\hline \multicolumn{8}{|c|}{ Fiancial information } \\
\hline Last log earnings per day & 1.62 & 1.58 & 1.53 & 1.65 & 1.57 & 1.63 & 1.63 \\
\hline Remaining UB claim & 21.60 & 9.91 & 10.33 & 16.93 & 11.01 & 18.74 & 18.90 \\
\hline Last earnings missing & 0.03 & 0.03 & 0.05 & 0.02 & 0.02 & 0.03 & 0.03 \\
\hline \multicolumn{8}{|c|}{ Employment history ${ }^{* *}$} \\
\hline Duration last employment & 28.07 & 20.04 & 20.20 & 28.31 & 23.33 & 31.66 & 33.29 \\
\hline \multicolumn{8}{|c|}{ Mean Duration in UE** } \\
\hline Overall History & 2.93 & 4.69 & 4.72 & 3.75 & 3.63 & 3.17 & 2.88 \\
\hline 5 years before UE entry & 2.23 & 4.36 & 4.23 & 2.99 & 3.13 & 2.16 & 1.98 \\
\hline 2 years before UE entry & 1.27 & 2.59 & 2.42 & 1.43 & 1.62 & 0.98 & 0.84 \\
\hline \multicolumn{8}{|c|}{ Mean Duration in $E^{* *}$} \\
\hline Overall History & 19.00 & 17.77 & 14.77 & 20.08 & 17.42 & 21.35 & 21.78 \\
\hline 5 years before UE entry & 21.16 & 15.54 & 14.39 & 21.09 & 17.27 & 23.63 & 24.83 \\
\hline 2 years before UE entry & 13.27 & 9.65 & 10.09 & 13.65 & 11.30 & 14.58 & 15.05 \\
\hline \multicolumn{8}{|c|}{ Mean Duration in OLF** } \\
\hline Overall History & 5.82 & 4.59 & 6.63 & 5.26 & 6.14 & 6.18 & 6.61 \\
\hline 5 years before UE entry & 1.50 & 1.54 & 1.83 & 1.32 & 1.55 & 1.39 & 1.53 \\
\hline 2 years before UE entry & 0.37 & 0.40 & 0.39 & 0.30 & 0.40 & 0.31 & 0.31 \\
\hline \multicolumn{8}{|c|}{ Time in program ${ }^{* *}$} \\
\hline Overall History & 0.69 & 3.67 & 2.93 & 1.52 & 3.02 & 1.54 & 1.40 \\
\hline 5 years before UE entry & 0.67 & 3.62 & 2.90 & 1.51 & 2.97 & 1.53 & 1.39 \\
\hline 2 years before UE entry & 0.33 & 2.44 & 1.97 & 1.00 & 2.10 & 1.02 & 0.89 \\
\hline \multicolumn{8}{|c|}{ Number of previous programs } \\
\hline Overall History & 0.43 & 1.71 & 1.38 & 0.94 & 1.50 & 0.89 & 0.83 \\
\hline 5 years before UE entry & 0.26 & 1.28 & 0.98 & 0.70 & 1.09 & 0.62 & 0.59 \\
\hline 2 years before UE entry & 0.12 & 0.77 & 0.61 & 0.43 & 0.68 & 0.38 & 0.38 \\
\hline \multicolumn{8}{|c|}{ Time in child care ${ }^{* *}$} \\
\hline Overall History & 7.21 & 6.24 & 7.92 & 6.44 & 6.98 & 9.01 & 7.88 \\
\hline 5 years before UE entry & 2.14 & 1.58 & 2.60 & 1.97 & 1.99 & 2.64 & 2.10 \\
\hline 2 years before UE entry & 0.38 & 0.19 & 0.51 & 0.36 & 0.45 & 0.53 & 0.40 \\
\hline \multicolumn{8}{|c|}{ Fraction of the entire observation period in * } \\
\hline UE & 12.05 & 21.85 & 20.88 & 14.23 & 17.77 & 11.65 & 10.58 \\
\hline E & 67.92 & 59.23 & 52.57 & 66.77 & 60.23 & 67.35 & 67.81 \\
\hline Others & 20.03 & 18.93 & 26.56 & 19.00 & 22.00 & 21.00 & 21.61 \\
\hline \multicolumn{8}{|c|}{ Last program* } \\
\hline $\mathrm{OM}$ & 0.95 & 1.44 & 0.92 & 0.72 & 2.21 & 0.56 & 0.78 \\
\hline SEE & 0.12 & 23.09 & 0.77 & 0.23 & 0.88 & 0.22 & 0.10 \\
\hline NSP & 0.08 & 0.58 & 16.77 & 0.11 & 0.66 & 0.10 & 0.09 \\
\hline AJS & 1.23 & 4.18 & 2.00 & 17.20 & 2.21 & 1.91 & 1.67 \\
\hline $\mathrm{JC}$ & 0.07 & 0.87 & 0.15 & 0.04 & 14.35 & 0.14 & 0.14 \\
\hline QM & 1.43 & 3.75 & 3.23 & 3.49 & 5.08 & 14.74 & 2.30 \\
\hline CS & 1.76 & 6.06 & 7.85 & 3.83 & 4.64 & 3.18 & 14.41 \\
\hline Others & 2.27 & 4.47 & 4.31 & 3.14 & 7.06 & 3.43 & 3.88 \\
\hline \multicolumn{8}{|c|}{ UE information* } \\
\hline Entry 1st quarter & 26.61 & 31.89 & 43.54 & 30.68 & 28.92 & 29.18 & 27.69 \\
\hline Entry 2nd quarter & 23.09 & 24.10 & 20.31 & 25.59 & 20.09 & 23.80 & 22.94 \\
\hline Entry 3rd quarter & 22.56 & 21.65 & 23.23 & 24.95 & 25.83 & 24.66 & 25.87 \\
\hline Entry 4th quarter & 27.74 & 22.37 & 12.92 & 18.79 & 25.17 & 22.36 & 23.50 \\
\hline Time in UE until (hyp.) program entry ** & 3.08 & 7.83 & 6.29 & 5.66 & 7.53 & 4.90 & 4.87 \\
\hline \multicolumn{8}{|c|}{ Regional information* } \\
\hline UE rate in 2000 & 7.00 & 6.70 & 6.86 & 8.50 & 6.22 & 7.22 & 6.69 \\
\hline
\end{tabular}




\begin{tabular}{|c|c|c|c|c|c|c|c|}
\hline Fraction of UA recipients in 2001 & 32.34 & 32.04 & 31.66 & 43.50 & 28.08 & 35.17 & 32.14 \\
\hline Fraction long-term unemployed in 2000 & 19.68 & 18.96 & 20.36 & 29.22 & 14.97 & 21.99 & 18.93 \\
\hline Fraction of unemplloyed aged 50+ in 2000 & 21.03 & 20.29 & 21.24 & 26.14 & 17.58 & 22.45 & 20.44 \\
\hline Fraction of adolescents in 2000 & 14.84 & 15.20 & 15.77 & 11.87 & 16.05 & 14.14 & 14.99 \\
\hline Fraction of foreigners in 2000 & 9.63 & 9.56 & 7.99 & 9.86 & 9.20 & 9.64 & 9.61 \\
\hline \multicolumn{8}{|c|}{ Federal state* } \\
\hline Burgenland & 3.59 & 10.82 & 2.92 & 1.13 & 20.09 & 4.22 & 2.39 \\
\hline Carienthia & 7.37 & 4.91 & 5.38 & 1.00 & 5.96 & 7.43 & 4.28 \\
\hline Lower Austria & 16.80 & 18.90 & 38.62 & 11.65 & 7.95 & 19.62 & 7.42 \\
\hline Upper Austria & 16.49 & 27.99 & 3.08 & 4.70 & 41.28 & 14.31 & 25.35 \\
\hline Salzburg & 6.27 & 5.19 & 0.15 & 1.38 & 2.43 & 4.35 & 8.72 \\
\hline Styria & 13.55 & 10.53 & 32.62 & 10.24 & 10.60 & 13.51 & 12.04 \\
\hline Tyrol & 7.38 & 2.45 & 3.08 & 1.61 & 1.55 & 3.43 & 9.49 \\
\hline Vorarlberg & 3.74 & 0.58 & 7.69 & 1.99 & 0.00 & 2.50 & 5.69 \\
\hline Vienna & 23.44 & 17.32 & 5.08 & 65.03 & 7.28 & 29.51 & 23.26 \\
\hline Missing & 1.37 & 1.30 & 1.38 & 1.27 & 2.87 & 1.12 & 1.36 \\
\hline \multicolumn{8}{|c|}{ Others* } \\
\hline Metropolitan area >1 Mio. & 23.44 & 17.32 & 5.08 & 65.03 & 7.28 & 29.51 & 23.26 \\
\hline Big city [100'000 -1 Mio. ] & 12.24 & 9.24 & 11.54 & 5.46 & 8.61 & 11.46 & 19.17 \\
\hline Medium size city <100'000 & 11.20 & 14.14 & 16.00 & 5.17 & 17.00 & 10.71 & 13.21 \\
\hline Urban area & 6.85 & 7.65 & 8.92 & 5.17 & 2.21 & 8.34 & 3.94 \\
\hline Industrial area & 34.11 & 41.56 & 47.23 & 14.50 & 54.53 & 32.15 & 32.14 \\
\hline Tourism & 10.80 & 8.80 & 9.85 & 3.40 & 7.51 & 6.72 & 6.91 \\
\hline Missing & 1.37 & 1.30 & 1.38 & 1.28 & 2.87 & 1.12 & 1.37 \\
\hline \multicolumn{8}{|c|}{ Employment status after (hyp.) program start* } \\
\hline Employed after 1 year & 61.95 & 37.27 & 41.05 & 53.06 & 37.23 & 50.97 & 59.01 \\
\hline Employed after 2 years & 63.51 & 45.30 & 49.50 & 57.88 & 46.87 & 62.39 & 68.21 \\
\hline Employed after 3 years & 64.45 & 49.36 & 53.60 & 58.92 & 53.02 & 65.52 & 69.77 \\
\hline Cumulated employment after 1 year ** & 6.19 & 2.74 & 2.74 & 4.22 & 3.11 & 3.59 & 4.72 \\
\hline Cumulated employment after 2 years $* *$ & 13.67 & 7.76 & 8.29 & 10.52 & 7.91 & 10.24 & 12.08 \\
\hline Cumulated employment after 3 years ${ }^{* *}$ & 21.15 & 13.05 & 14.05 & 17.00 & 13.07 & 17.50 & 19.81 \\
\hline
\end{tabular}

Note: $\left(^{*}\right)$ numbers in $\left.\%,{ }^{* *}\right)$ numbers in months. UE: unemployment, E: employment, OM: orientation measures, SEE: socio-economic enterprise. NSP: non-profit sector project, JC: job coaching, AJS: active job search, QM: qualification measure, CS: course subsidy. UB unemployment benefits, UA unemployment assistance.

Table 2a: Dropping observations in parental leave right before the (hyp.) program start

\begin{tabular}{|c|c|c|c|c|c|c|c|c|c|c|c|c|c|c|}
\hline \multirow[b]{2}{*}{ Gender } & \multicolumn{2}{|c|}{ NON } & \multicolumn{2}{|c|}{ SEE } & \multicolumn{2}{|c|}{ NPS } & \multicolumn{2}{|c|}{ AJS } & \multicolumn{2}{|c|}{ JC } & \multicolumn{2}{|c|}{ QM } & \multicolumn{2}{|c|}{ CS } \\
\hline & $\mathrm{M}$ & $\mathrm{F}$ & $\mathrm{M}$ & $\mathrm{F}$ & $\mathrm{M}$ & $\mathrm{F}$ & $\mathrm{M}$ & $\mathrm{F}$ & $\mathrm{M}$ & $\mathrm{F}$ & $\mathrm{M}$ & $F$ & $\mathrm{M}$ & F \\
\hline Cases & 51849 & 53493 & 350 & 343 & 301 & 349 & 9654 & 9662 & 210 & 243 & 6896 & 11337 & 4553 & 5597 \\
\hline No parental leav & right be & ore the & hypo & etical & rogra & entry & & & & & & & & \\
\hline Remaining cases & 51739 & 52588 & 350 & 343 & 301 & 349 & 9653 & 9660 & 210 & 243 & 6896 & 11335 & 4550 & 5590 \\
\hline
\end{tabular}




\section{Results of the binary probit models}

Table 2: Estimation results of all probit specifications for women

\begin{tabular}{|c|c|c|c|c|c|c|c|c|c|c|c|}
\hline \multicolumn{2}{|c|}{ SEE versus non-partic. } & \multicolumn{2}{|c|}{ NPS versus non-partic. } & \multicolumn{2}{|c|}{ JC versus non-partic. } & \multicolumn{2}{|c|}{\begin{tabular}{|l|} 
AJS versus non-partic. \\
\end{tabular}} & \multicolumn{2}{|c|}{ QM versus non-partic. } & \multicolumn{2}{|c|}{ CS versus non-partic. } \\
\hline Const & $-4.765^{\star \star \star}$ & Const & $-3.082^{\star * \star}$ & Const & $-3.099^{\star \star \star}$ & Const & $-2.468^{\star \star \star}$ & Const & $-1.692^{\star \star \star}$ & Const & $-2.360^{* \star \star}$ \\
\hline DISAB & $0.691 * \star \star$ & DISAB & 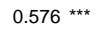 & DISAB & 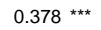 & DISAB & $0.247^{\star \star \star *}$ & DISAB & $0.599 * \star \star$ & DISAB & $0.300 * \star \star$ \\
\hline FOREIGN & 0.055 & FOREIGN & -0.404 & FOREIGN & -0.304 & FOREIGN & -0.104 & FOREIGN & 0.040 & FOREIGN & 0.001 \\
\hline FAMSIN & -0.059 & FAMSIN & 0.090 & FAMSIN & $0.280 * \star *$ & FAMSIN & -0.009 & FAMSIN & -0.060 ** & FAMSIN & 0.020 \\
\hline FAMDIV & -0.016 & FAMDIV & 0.212 ** & FAMDIV & 0.219 ** & FAMDIV & 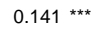 & FAMDIV & $0.200 * \star *$ & FAMDIV & $0.141 * \star \star$ \\
\hline FAMCOM & 0.052 & FAMCOM & 0.180 & FAMCOM & 0.104 & FAMCOM & 0.011 & FAMCOM & -0.041 & FAMCOM & -0.024 \\
\hline FAMMISS & 0.256 * & FAMMISS & 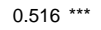 & FAMMISS & 0.371 ** & FAMMISS & $0.179 * \star \star$ & FAMMISS & 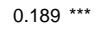 & FAMMISS & $0.153 \star \star \star *$ \\
\hline EDMIS & -0.073 & EDMIS & -0.219 & EDMIS & -0.130 & EDMIS & 0.024 & EDMIS & 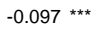 & EDMIS & $-0.122 * \star *$ \\
\hline ED1 & 0.231 ** & ED1 & -0.027 & ED1 & 0.159 ** & ED1 & $0.070 * \star *$ & ED1 & -0.112 * & ED1 & $-0.140 * \star *$ \\
\hline ED3 & -0.165 & ED3 & -0.086 & ED3 & $-0.510 * \star *$ & ED3 & -0.014 & ED3 & -0.043 * & ED3 & 0.002 \\
\hline JAGGR & 0.121 & JAGGR & 0.104 & JAGGR & 0.143 & JAGGR & -0.189 ** & JAGGR & -0.076 & JAGGR & 0.054 \\
\hline JJUR & -0.140 & JJUR & 0.114 & JJUR & 0.007 & JJUR & 0.131 ** & JJUR & 0.314 ** & JJUR & 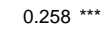 \\
\hline JHEALTH & -0.302 ** & JHEALTH & -0.205 & JHEALTH & -0.228 & JHEALTH & $-0.081 * *$ & JHEALTH & $0.090^{* \star *}$ & JHEALTH & $0.196 * * *$ \\
\hline JTRADE & -0.124 & JTRADE & -0.178 * & JTRADE & 0.013 & JTRADE & $0.075^{* \star \star}$ & JTRADE & $0.136 * \star *$ & JTRADE & 0.068 ** \\
\hline JSERV & -0.046 & JSERV & $-0.158 *$ & JSERV & -0.142 & JSERV & $-0.149 * \star *$ & JSERV & -0.090 * & JSERV & $-0.055 *$ \\
\hline JMISS & -0.353 *** & JMISS & 0.267 ** & JMISS & 0.016 & JMISS & -0.394 * & JMISS & 0.001 & JMISS & -0.018 \\
\hline EMPSM & -0.251 *k* & EMPSM & -0.211 *** & EMPSM & -0.064 & EMPSM & -0.037 * & EMPSM & -0.042 ** & EMPSM & -0.025 \\
\hline EMPBIG & -0.006 & EMPBIG & -0.052 & EMPBIG & -0.111 & EMPBIG & 0.014 & EMPBIG & -0.040 ** & EMPBIG & $-0.045 *$ \\
\hline EMPHUGE & 0.015 & EMPHUGE & $-0.173 * *$ & EMPHUGE & 0.137 & EMPHUGE & -0.021 & EMPHUGE & -0.053 ** & EMPHUGE & -0.117 *** \\
\hline EMPMISS & $-0.430 * * *$ & EMPMISS & 0.058 & EMPMISS & -0.278 * & EMPMISS & $-0.185 * \star$ & EMPMISS & -0.242 *** & EMPMISS & $-0.309 * \star *$ \\
\hline ALQ00 & -0.112 *** & ALQ00 & 0.027 & ALQ00 & $0.079 * *$ & ALQ00 & 0.013 & ALQ00 & -0.038 *k & ALQ00 & -0.011 \\
\hline LZAOOZ & $0.355 * * *$ & LZAOOZ & -0.052 & LZAOOZZ & -0.153 & LZAOOZ & -0.028 & LZAOOZ & 0.164 *** & LZAOOZ & $0.129 * * \star$ \\
\hline JUG00Z & 0.356 * & JUGO0Z & 0.102 & JUG00Z & -0.178 & JUGOOZ & -0.177 * & JUG00Z & $0.073 * *$ & JUG00Z & 0.049 \\
\hline AUSLO0Z & -0.058 & AUSLO0Z & 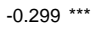 & AUSLO0Z & -0.070 & AUSLO0Z & $-0.045 *$ & AUSLO0Z & 0.003 & AUSLO0Z & -0.011 \\
\hline REGIND & $0.281 * \star *$ & REGIND & $0.397 * \star$ & REGIND & -0.082 & REGIND & 0.009 & REGIND & $0.199 \star \star \star \star$ & REGIND & 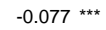 \\
\hline REGTOUR & 0.666 * & REGTOUR & -0.217 & REGTOUR & -0.061 & REGTOUR & $0.249 * \star \star$ & REGTOUR & $0.100 *$ & REGTOUR & -0.135 ** \\
\hline VVZ & 0.121 *** & VVz & 0.039 & VVZ & -0.048 & VVZ & $0.085 * \star *$ & Vvz & -0.154 *** & VVz & 0.103 *** \\
\hline JOBDIFF & $0.330 * \star \star$ & JOBDIFF & -0.028 & JOBDIFF & 0.000 & JOBDIFF & $0.352 * \star *$ & JOBDIFF & 0.234 *** & JOBDIFF & $0.134 * \star \star$ \\
\hline LLASTINC & 0.362 * & LLASTINC & -0.003 & LLASTINC & -0.301 & LLASTINC & 0.098 *** & LLASTINC & -0.074 *** & LLASTINC & $0.183^{\star} \star \star \star$ \\
\hline LINCLOW & 0.163 & LINCLOW & -0.115 & LINCLOW & 0.126 & LINCLOW & -0.052 * & LINCLOW & $-0.088 * \star *$ & LINCLOW & 0.026 \\
\hline FOINCLOW & 0.021 & FOINCLOW & 0.213 & FOINCLOW & $-0.360 *$ & FOINCLOW & -0.052 & FOINCLOW & 0.050 & FOINCLOW & -0.117 ** \\
\hline DURLEMPH & 0.073 & DURLEMPH & -0.051 & DURLEMPH & -0.119 & DURLEMPH & $-0.174 * \star \star$ & DURLEMPH & $0.144^{* * *}$ & DURLEMPH & 0.280 k \\
\hline MDURE2Z & -0.035 & MDURE2Z & 0.065 & MDURE2Z & 0.037 & MDURE2Z & $0.105^{* \star \star}$ & MDURE2Z & $0.111 * \star *$ & MDURE2Z & $0.038 *$ \\
\hline MDURUE2Z & 0.081 & MDURUE2Z & -0.005 & MDURUE2Z & -0.051 & MDURUE2Z & $-0.679 * \star *$ & MDURUE2Z & $-0.503 * \star *$ & MDURUE2Z & -1.470 * \\
\hline MDUOLF2Z & 0.218 & MDUOLF2Z & -0.444 ** & MDUOLF2Z & 0.046 & MDUOLF2Z & 0.014 & MDUOLF2Z & 0.066 & MDUOLF2Z & 0.019 \\
\hline FRACUE & 0.179 & FRACUE & 0.106 & FRACUE & -0.116 & FRACUE & -0.637 * & FRACUE & -0.774 *** & FRACUE & -0.512 *** \\
\hline FRACE & -0.347 * & FRACE & $-0.292 * *$ & FRACE & -0.166 & FRACE & 0.148 *** & FRACE & -0.045 & FRACE & -0.100 ** \\
\hline NOCLENTR & 0.013 & NOCLENTR & 0.026 & NOCLENTR & -0.130 & NOCLENTR & -0.086 ** & NOCLENTR & -0.059 * & NOCLENTR & -0.053 \\
\hline AGENTPR & 0.008 & AGENTPR & -0.006 & AGENTPR & -0.004 & AGENTPR & 0.001 & AGENTPR & $-0.005 * \star$ & AGENTPR & 0.000 \\
\hline DIFLEMPZ & $0.295 * *$ & DIFLEMPZ & $0.531 * \star *$ & DIFLEMPZ & 0.677 *** & DIFLEMPZ & 0.688 * & DIFLEMPZ & $0.550 * * \star$ & DIFLEMPZ & 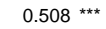 \\
\hline LASTINCM & $1.014 * \star *$ & EDACAD & 0.127 & EDACAD & 0.496 * & EDACAD & -0.014 & EDNO & $-0.219 * \star \star$ & EDADV & $0.054 *$ \\
\hline FOEDBAS & -0.127 & BNOE & 0.309 ** & LASTINCM & -0.644 & FOEDAP & 0.198 ** & EDADV & 0.121 *** & LASTINCM & $0.593 * \star \star$ \\
\hline BBGL & 0.005 & BOOE & $-0.384 * \star *$ & BBGL & 0.008 & FOEDHI & 0.140 & EDACAD & $-0.062 *$ & FOSINGL & 0.000 \\
\hline BOOE & 0.016 & BSTM & $0.555^{* \star \star}$ & BKTN & 0.192 & BBGL & -0.219 ** & BBGL & $0.233 * \star *$ & FONOCL & 0.163 ** \\
\hline BVBG & $-0.875 * * *$ & BVBG & -0.054 & BNOE & $0.637 * \star \star *$ & BKTN & -0.538 * & BKTN & 0.050 & BBGL & -0.060 \\
\hline QUART1 & 0.243 ** & BWIE & -0.092 & BOOE & $0.898 * \star \star *$ & BNOE & $0.422 * \star *$ & BNOE & 0.001 & BKTN & -0.045 \\
\hline QUART4 & -0.009 & QUART1 & $0.627 * * *$ & BSBG & 0.065 & BOOE & $0.151 * * *$ & BTIR & -0.137 ** & BNOE & $-0.341 * * *$ \\
\hline INDTOU & 0.009 & QUART4 & -0.144 & BTIR & -0.069 & BSTM & $0.459 * \star \star$ & BVBG & 0.014 & BOOE & 0.428 *** \\
\hline INDAUTH & -0.462 *** & INDPROD & -0.292 *** & BSTM & 0.140 & BVBG & $0.533 * \star *$ & BWIE & 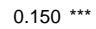 & BSBG & $0.453 * \star \star$ \\
\hline INDTRTEL & -0.331 & INDTOU & $-0.459 * \star \star$ & |INDTOU & -0.052 & BWIE & $1.253 * \star *$ & QUART1 & 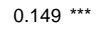 & BTIR & $0.504 * \star \star *$ \\
\hline INDTCON & -0.184 & INDAUTH & 0.147 & INDPROD & 0.162 * & QUART1 & $0.102 * \star *$ & QUART4 & $-0.159 * \star *$ & BVBG & $0.477^{\star * *}$ \\
\hline INDSHC & 0.151 & INDTRTEL & -0.233 & |INDTRTEL & -0.078 & QUART4 & -0.335 * & INDTOU & 0.005 & BWIE & $-0.459 * \star *$ \\
\hline INDOTH & 0.127 * & INDTCON & -0.841 ** & INDTCON & -0.485 * & INDTOU & -0.065 ** & INDAUTH & -0.014 & QUART1 & 0.016 \\
\hline MDUREZ & 0.048 * & INDCOM & -0.222 *** & NUMPR2 & 0.161 *** & INDAUTH & 0.046 & INDTCON & 0.103 ** & QUART4 & -0.078 ** \\
\hline NUMPR2 & 0.086 & INDSHC & 0.214 ** & |LPRFBT & $1.914 * * \star$ & INDTCON & 0.133 ** & INDSHC & $0.087^{\star \star \star *}$ & INDTOU & $-0.074 * * *$ \\
\hline NUMPR5 & $0.103 * \star * \star$ & NUMPR2 & $0.146 * \star *$ & LPRFBQ & -0.153 & INDSHC & -0.007 & INDBAIT & 0.035 & INDAUTH & -0.013 \\
\hline LPRCOUNS & 0.117 & LPRCOUNS & -0.355 & LPRKK & 0.028 & INDCOM & 0.141 ** & INDCOM & $0.133 * \star \star$ & INDTCON & 0.040 \\
\hline LPRSOB & $2.369 * \star * \star$ & |LPRGBP & $2.445 * \star *$ & LPROTH & 0.110 & INDTRTEL & $0.072 *$ & |INDTRTEL & $0.119 * \star *$ & INDSHC & $0.068 * *$ \\
\hline LPRFBA & 0.170 & |LPRKK & $0.540 * * *$ & FOALQ00Z & 0.670 ** & INDPROD & $0.185 * \star *$ & |INDPROD & $0.140 * \star *$ & MDUOLF5Z & $0.032 *$ \\
\hline FODURE2Z & 0.234 ** & FODUROLZ & $0.149 * \star * \star$ & NCLFBQ & 1.032 & INDEWM & -0.048 & MDURUEZ & 0.104 *** & NUMPR2 & $0.129 * \star *$ \\
\hline FODUREZ & $-0.347 * \star *$ & FODUREZ & 0.052 & WIEFSIN & 0.361 * & INDBAIT & -0.017 & NUMPR2 & $0.171 * \star \star$ & NUMPR5 & 0.027 * \\
\hline DIFFRAUE & 0.079 & DIFGBP & -0.068 & QU1ED1 & -0.115 & MDURUEZ & 0.124 **ᄎ & NUMPR5 & $0.047^{\star \star \star *}$ & LPRFBA & 0.182 \\
\hline DIFCOUNS & -0.498 & DIFKK & -0.243 & QU1REIND & 0.173 * & NUMPR2 & 0.144 *ᄎ* & FODUUE5Z & -0.213 ** & LPRFBT & 0.161 \\
\hline DIFSOB & -0.177 & DISDIFL & $-0.405 * \star *$ & QU4REIND & -0.202 & NUMPR5 & $0.062 * \star * *$ & LPRCOUNS & -0.134 & LPRFBQ & 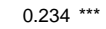 \\
\hline DIFJOB & $-0.300 * \star *$ & DISGBP & -0.172 & FONUMPR2 & $0.221 *$ & LPRCOUNS & $-0.141 *$ & LPRSOB & 0.205 & LPRKK & 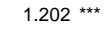 \\
\hline NCLSOB & -0.305 & DIDUUE2Z & 0.491 ** & DIFBGL & $0.700 * \star \star$ & LPRSOB & 0.148 & LPRFBA & $0.197 * \star \star$ & LPRUGP & 0.456 ** \\
\hline DISCOUNS & 0.137 & RINDAUSL & $-0.521 * * \star$ & DIFNOE & -0.299 ** & LPRGBP & 0.317 & |LPRFBT & 0.225 & LPRUGPKK & 0.598 * \\
\hline DISSOB & -0.099 & LOWREIND & 0.328 ** & DIFWIE & -0.464 *ᄎ* & LPRFBA & $1.590 * \star *$ & LPRFBQ & $1.344^{* \star *}$ & LPROTH & 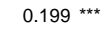 \\
\hline DISFBQ & $0.700 * * *$ & LOWRETOU & 0.452 ** & DIFQU4 & 0.089 & LPRFBQ & $0.463 * \star *$ & LPRKK & 0.216 *** & FODUREZ & $-0.098 * \star *$ \\
\hline DISDIFL & $-0.430 * \star *$ & QU1REIND & 0.125 & NUIPROD & -0.211 ** & LPRKK & $0.301 * \star *$ & |LPRUGP & $0.393 * *$ & FODUUE2Z & -0.265 \\
\hline
\end{tabular}


Table 2 continued

\begin{tabular}{|c|c|c|c|c|c|c|c|c|c|c|c|}
\hline \begin{tabular}{|l} 
DISED1 \\
DISREIND \\
DISIILOW \\
FOSOB \\
WIEDIS \\
LOWFSIN \\
DIFBGL \\
DIFOOE \\
DIFSTM \\
DIFQU1 \\
DIFQU4 \\
DISHC \\
QU1SOB \\
RINDED1 \\
MDURUE2Q \\
DIFLEMPQ \\
FRACAMID \\
FRACAHIG
\end{tabular} & $\begin{array}{l}-0.241 \\
-0.571 \text { *** } \\
0.191 \\
0.348 \\
-0.374 \text { * } \\
0.201 \\
0.624 * * * \\
0.301 * * * \\
-0.186 \text { ** } \\
-0.227 \text { ** } \\
0.057 \\
0.437 \text { ** } \\
0.075 \\
-0.285 * * * \\
0.112 \\
0.109 * * * \\
0.120 \\
0.695 * * *\end{array}$ & $\begin{array}{l}\text { QU4REIND } \\
\text { DINUMPR5 } \\
\text { DDFNOE } \\
\text { DIFSTM } \\
\text { DIFVBG } \\
\text { DIFQU1 } \\
\text { DIFQU4 } \\
\text { RTOUED3 } \\
\text { ED3JHEA } \\
\text { EMISED } \\
\text { JMISREIN } \\
\text { NCLDIFL } \\
\text { NCLINCL } \\
\text { DIFJED1 } \\
\text { MOFPR }\end{array}$ & 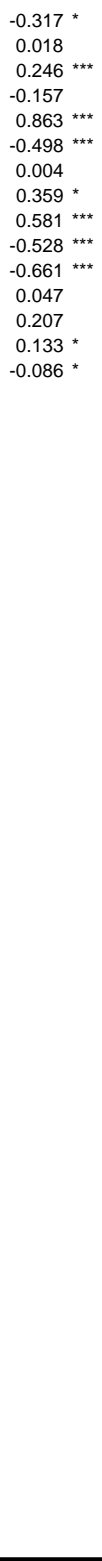 & \begin{tabular}{|l} 
QU4OTH \\
BWIEED1 \\
BWIEED3
\end{tabular} & $\begin{array}{l}-0.679 \text { * } \\
-0.081 \\
0.838 \text { * }\end{array}$ & 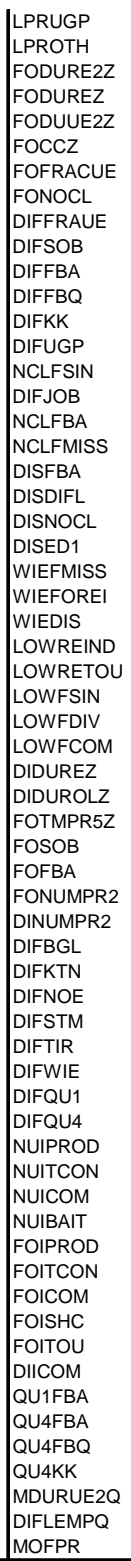 & 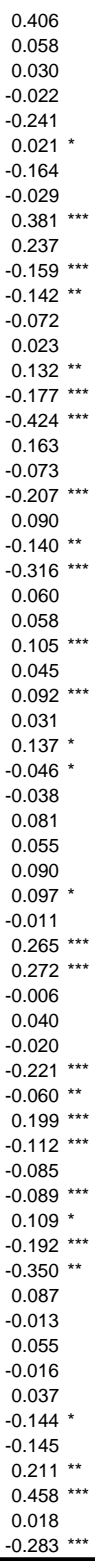 & 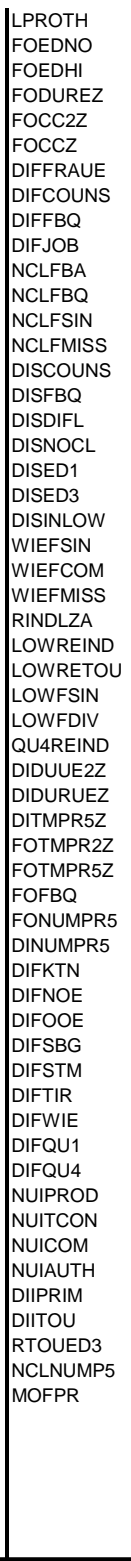 & 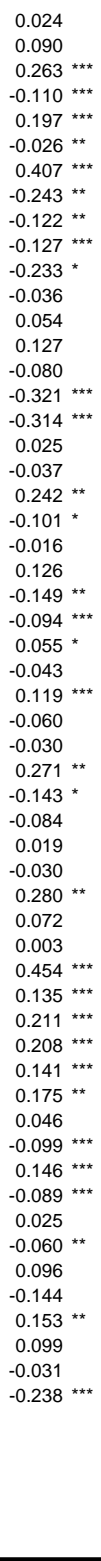 & \begin{tabular}{|l} 
FODUROLZ \\
DIFFRAUE \\
DIFFBA \\
DIFKK \\
DIFJOB \\
NCLFBA \\
NCLKK \\
NCLFSIN \\
NCLLFMISS \\
NCLFK \\
DISK \\
DISDIFL \\
DISRETOU \\
DIDUE2Z \\
WIEDIS \\
DITMPR5Z \\
WIEFOREI \\
FONUMPR5 \\
DINUMPR5 \\
DIFNOE \\
DIFOOE \\
DFSTM \\
DIFVBG \\
DIFWIE \\
DIFQU4 \\
NUITCON \\
NUICOM \\
QU4KK \\
RINDED1 \\
BWIEED1 \\
BWIEED3 \\
MDURUE2Q \\
DIFLEMPQ \\
MOFPR \\
\end{tabular} & 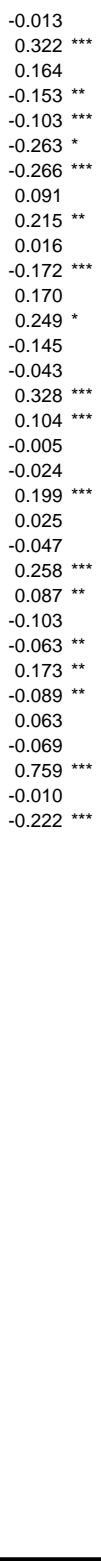 \\
\hline
\end{tabular}

Note: Positive coefficients denote that the respective variable contributes positively to the participation probability in the program listed on top of each column. $\left(^{*}\right)$ significance on the 10 percent, $\left.{ }^{\star \star}\right) 5$ percent, and $\left(^{\star}\right) 1$ percent level. SEE: socio-economic enterprise. NSP: non-profit sector project, JC: job coaching, AJS: active job search, QM: qualification measure, CS: course subsidy. The abbreviations used are explained in the following Table 4. 
Table 3: Estimation results of all probit specifications for men

\begin{tabular}{|c|c|c|c|c|c|c|c|c|c|c|c|}
\hline \multicolumn{2}{|c|}{ SEE versus non-partic. } & \multicolumn{2}{|c|}{ NPS versus non-partic. } & \multicolumn{2}{|c|}{$\begin{array}{l}\text { JC versus non-partic. } \\
\end{array}$} & \multicolumn{2}{|c|}{ AJS versus non-partic. } & \multicolumn{2}{|c|}{\begin{tabular}{|l|} 
QM versus non-partic. \\
\end{tabular}} & \multicolumn{2}{|c|}{\begin{tabular}{|l} 
CS versus non-partic. \\
\end{tabular}} \\
\hline Const & $-4.289^{\star \star \star}$ & Const & $-4.744^{\star \star \star}$ & Const & $-2.923^{\star \star \star}$ & Const & $-2.730^{\star \star \star}$ & Const & $-2.079^{* \star \star}$ & Const & $-2.419^{\star \star \star}$ \\
\hline DISAB & $0.702 * \star \star *$ & DISAB & $0.792 * * *$ & DISAB & 0.165 & DISAB & $0.595 * * *$ & DISAB & $0.837 * \star *$ & DISAB & 0.466 *** \\
\hline FOREIGN & 0.100 & FOREIGN & $-0.323 *$ & FOREIGN & -0.657 *** & FOREIGN & -0.302 *** & FOREIGN & -0.059 & FOREIGN & -0.002 \\
\hline FAMSIN & -0.063 & FAMSIN & 0.159 ** & FAMSIN & $0.150 *$ & FAMSIN & 0.008 & FAMSIN & $-0.069 * \star \star$ & FAMSIN & $-0.107 * \star \star$ \\
\hline FAMDIV & 0.086 & FAMDIV & 0.102 & FAMDIV & 0.089 & FAMDIV & 0.049 & FAMDIV & -0.004 & FAMDIV & 0.003 \\
\hline FAMCOM & 0.017 & FAMCOM & -0.071 & FAMCOM & 0.104 & FAMCOM & -0.013 & FAMCOM & -0.042 & FAMCOM & -0.046 \\
\hline FAMMISS & 0.119 & FAMMISS & 0.361 ** & FAMMISS & 0.073 & FAMMISS & $0.284 * \star *$ & FAMMISS & 0.074 & FAMMISS & 0.016 \\
\hline EDMIS & -0.262 & EDMIS & 0.031 & EDMIS & 0.113 & EDMIS & $0.111 * \star *$ & EDMIS & 0.027 & EDMIS & 0.015 \\
\hline ED1 & 0.220 ** & ED1 & -0.029 & ED1 & 0.222 ** & ED1 & 0.046 ** & ED1 & -0.016 & ED1 & $-0.097 * \star *$ \\
\hline ED3 & -0.262 ** & ED3 & -0.325 * & ED3 & -0.060 & ED3 & 0.012 & ED3 & -0.021 & ED3 & 0.042 \\
\hline JAGGR & -0.091 & JAGGR & 0.349 * & JAGGR & 0.153 & JAGGR & 0.066 & JAGGR & -0.110 & JAGGR & -0.142 \\
\hline JJUR & -0.150 & JJUR & -0.237 & JJUR & -0.068 & JJUR & $0.187 * \star \star$ & JJUR & $0.160 * \star *$ & JJUR & $0.127 * \star \star$ \\
\hline JENG & -0.084 & JENG & -0.441 ** & JENG & -0.224 & JENG & $0.213 * \star *$ & JENG & $0.160 * * *$ & JENG & 0.146 *** \\
\hline JHEALTH & -0.225 & JHEALTH & -0.378 * & JHEALTH & 0.064 & JHEALTH & 0.021 & JHEALTH & 0.071 & JHEALTH & 0.142 *** \\
\hline JTRADE & -0.101 & JTRADE & 0.088 & JTRADE & $-0.295 * k$ & JTRADE & $0.097 * \star *$ & JTRADE & $0.079 * * *$ & JTRADE & $0.085^{* \star *}$ \\
\hline JSERV & -0.216 * & JSERV & -0.251 * & JSERV & -0.014 & JSERV & $-0.115^{* * *}$ & JSERV & -0.018 & JSERV & 0.016 \\
\hline JMISS & $-0.299 * *$ & JMISS & 0.216 & JMISS & -0.192 & JMISS & $-0.293 * \star *$ & JMISS & 0.092 *** & JMISS & -0.018 \\
\hline EMPSM & -0.151 * & EMPSM & -0.253 *** & EMPSM & -0.019 & EMPSM & -0.076 *** & EMPSM & -0.118 *** & EMPSM & -0.033 \\
\hline EMPBIG & -0.059 & EMPBIG & -0.051 & EMPBIG & 0.024 & EMPBIG & $0.058 * \star *$ & EMPBIG & 0.078 *** & EMPBIG & -0.007 \\
\hline EMPHUGE & -0.072 & EMPHUGE & -0.036 & EMPHUGE & $0.328 * \star \star$ & EMPHUGE & 0.126 *** & EMPHUGE & 0.036 & EMPHUGE & -0.040 \\
\hline EMPMISS & -0.085 & EMPMISS & -0.002 & EMPMISS & -0.608 ** & EMPMISS & -0.177 *** & EMPMISS & -0.247 *** & EMPMISS & -0.216 *** \\
\hline ALQ00 & -0.024 & ALQ00 & 0.059 ** & ALQ00 & 0.031 & ALQ00 & $-0.040 * \star *$ & ALQ00 & -0.023 ** & ALQ00 & 0.013 \\
\hline LZAOOZ & 0.055 & LZAOOZ & -0.118 & LZAOOZ & $-0.315 * \star *$ & LZAOOZ & 0.125 *** & LZAOOZ & $0.103 * \star *$ & LZAOOZ & 0.036 \\
\hline JUG00Z & 0.348 ** & JUG00Z & 0.130 & JUGO0Z & 0.064 & JUG00Z & -0.108 ** & JUG00Z & 0.053 & JUG00Z & 0.123 ** \\
\hline AUSLO0Z & 0.115 & AUSLO0Z & -0.020 & AUSLO0Z & -0.134 & AUSLOOZ & $-0.044 *$ & AUSLO0Z & -0.005 & AUSLO0Z & 0.076 *** \\
\hline REGIND & 0.068 & REGIND & 0.157 & REGIND & -0.099 & REGIND & 0.066 ** & REGIND & 0.058 & REGIND & $-0.139 * \star \star$ \\
\hline REGTOUR & 0.070 & REGTOUR & -0.116 & REGTOUR & -0.149 & REGTOUR & $0.343 * \star *$ & REGTOUR & $0.137 * \star *$ & REGTOUR & -0.231 *** \\
\hline VVZ & -0.086 & VVZ & 0.077 ** & VVZ & -0.031 & VVZ & $0.105 * \star *$ & vVz & -0.171 *** & VVZ & $0.151 * \star *$ \\
\hline JOBDIFF & 0.215 & JOBDIFF & 0.130 * & JOBDIFF & 0.061 & JOBDIFF & $0.386 * \star *$ & JOBDIFF & 0.181 *** & JOBDIFF & 0.128 *** \\
\hline LLASTINC & 0.186 & LLASTINC & 0.122 & LLASTINC & -0.626 *** & LLASTINC & 0.020 & LLASTINC & -0.107 *** & LLASTINC & $0.138 *$ \\
\hline LINCLOW & 0.038 & LINCLOW & 0.317 *** & LINCLOW & 0.127 & LINCLOW & 0.005 & LINCLOW & -0.108 *** & LINCLOW & 0.017 \\
\hline FOINCLOW & 0.081 & FOINCLOW & 0.050 & FOINCLOW & 0.050 & FOINCLOW & -0.025 & FOINCLOW & 0.038 & FOINCLOW & 0.000 \\
\hline DURLEMPH & 0.043 & DURLEMPH & 0.346 & DURLEMPH & 0.344 & DURLEMPH & -0.287 *** & DURLEMPH & $0.115^{* *}$ & DURLEMPH & 0.133 ** \\
\hline MDURE2Z & -0.073 & MDURE2Z & 0.143 * & MDURE2Z & -0.004 & MDURE2Z & $0.185 * \star *$ & MDURE2Z & 0.169 *** & MDURE2Z & 0.113 *** \\
\hline MDURUE2Z & -0.151 & MDURUE2Z & 0.021 & MDURUE2Z & -0.467 & MDURUE2Z & -0.738 *** & MDURUE2Z & -0.758 *** & MDURUE2Z & $-1.796 * \star * \star$ \\
\hline MDUOLF2Z & -0.087 & MDUOLF2Z & 0.249 & MDUOLF2Z & 0.260 & MDUOLF2Z & 0.131 * & MDUOLF2Z & 0.264 *** & MDUOLF2Z & 0.083 \\
\hline FRACUE & $0.903 * \star$ & FRACUE & 0.257 & FRACUE & 0.444 & FRACUE & $-0.510 * \star *$ & FRACUE & -0.904 *** & FRACUE & $-0.536 * \star \star$ \\
\hline FRACE & -0.355 & FRACE & $-0.594 * * *$ & FRACE & -0.064 & FRACE & $0.090 *$ & FRACE & 0.085 & FRACE & 0.078 \\
\hline NOCLENTR & 0.151 & NOCLENTR & 0.187 & NOCLENTR & -0.235 & NOCLENTR & -0.119 ** & NOCLENTR & -0.046 & NOCLENTR & -0.077 \\
\hline AGENTPR & -0.007 & AGENTPR & 0.012 ** & AGENTPR & 0.007 & AGENTPR & $0.005 * \star *$ & AGENTPR & $-0.006 * \star *$ & AGENTPR & $-0.003 * *$ \\
\hline DIFLEMPZ & $0.865 * * \star$ & DIFLEMPZ & $0.604 * \star \star$ & DIFLEMPZ & 0.807 *** & DIFLEMPZ & $0.759 * * \star$ & DIFLEMPZ & $0.549 * \star \star$ & DIFLEMPZ & $0.542 * \star \star$ \\
\hline LASTINCM & -0.040 & EDACAD & $0.373 * *$ & EDACAD & -0.082 & EDACAD & -0.224 *** & EDNO & -0.252 *** & EDADV & 0.129 *** \\
\hline FOEDBAS & $-0.395 * * \star$ & $\mathrm{BNOE}$ & $0.901 * * *$ & LASTINCM & -0.839 ** & FOEDAP & 0.093 * & EDADV & 0.100 ** & LASTINCM & 0.352 ** \\
\hline BBGL & -0.323 & BOOE & -0.268 & BBGL & $0.694 * \star *$ & FOEDHI & 0.182 * & EDACAD & $-0.155 * \star *$ & FOSINGL & $0.164 * * *$ \\
\hline BOOE & 0.041 & BSTM & $0.824 * \star *$ & BKTN & 0.146 & BBGL & $-0.206 *$ & BBGL & 0.467 *** & FONOCL & $0.162 *$ \\
\hline BVBG & -0.822 ** & BVBG & 0.378 & BNOE & 0.377 & BKTN & $-0.542 * \star *$ & BKTN & $0.130 * *$ & BBGL & -0.075 \\
\hline QUART1 & $0.289 * \star$ & BWIE & -0.130 & BOOE & 0.658 *** & BNOE & 0.152 ** & BNOE & 0.110 ** & BKTN & -0.152 ** \\
\hline QUART4 & -0.274 * & QUART1 & 0.337 ** & BSBG & 0.171 & BOOE & 0.003 & BTIR & -0.201 *** & BNOE & $-0.539 * * \star$ \\
\hline INDTOU & $-0.425 * \star *$ & QUART4 & $-0.605 * \star *$ & BTIR & -0.536 & BSTM & 0.045 & BVBG & $-0.190 * \star *$ & BOOE & 0.088 \\
\hline INDAUTH & 0.151 & INDPROD & -0.105 & BSTM & 0.461 ** & BVBG & $0.300 * * *$ & BWIE & $0.231 * * *$ & BSBG & $0.201 * * *$ \\
\hline INDTRTEL & -0.085 & INDTOU & -0.273 ** & INDTOU & -0.285 & BWIE & $1.190 * \star \star$ & QUART1 & 0.082 ** & BTIR & $0.255^{* \star *}$ \\
\hline INDTCON & -0.105 & INDAUTH & 0.130 & INDPROD & 0.012 & QUART1 & 0.064 * & QUART4 & -0.061 & BVBG & 0.028 \\
\hline INDSHC & 0.260 * & INDTRTEL & $-0.766 * \star *$ & INDTRTEL & -0.107 & QUART4 & $-0.386 * \star *$ & |INDTOU & -0.050 & BWIE & $-0.531 * * *$ \\
\hline INDOTH & 0.176 ** & INDTCON & -0.226 * & INDTCON & -0.110 & INDTOU & -0.034 & INDAUTH & -0.123 ** & QUART1 & 0.010 \\
\hline MDUREZ & 0.043 & INDCOM & -0.229 ** & NUMPR2 & $0.190 * \star *$ & INDAUTH & -0.082 & INDTCON & $-0.105 * * *$ & QUART4 & -0.083 ** \\
\hline NUMPR2 & 0.125 ** & INDSHC & $0.389 * * *$ & |LPRFBT & $2.277^{\star \star * \star}$ & INDTCON & $-0.180 * * *$ & INDSHC & -0.037 & INDTOU & $-0.106 * \star *$ \\
\hline NUMPR5 & 0.078 ** & NUMPR2 & $0.319 * \star *$ & LPRFBQ & 0.308 & INDSHC & 0.000 & |INDBAIT & -0.086 * & INDAUTH & -0.045 \\
\hline LPRCOUNS & 0.852 ** & LPRCOUNS & -0.687 * & LPRKK & 0.174 & INDCOM & $0.156 * \star *$ & INDCOM & $0.130 * * *$ & INDTCON & $-0.155^{\star \star \star \star}$ \\
\hline LPRSOB & $2.313 * \star *$ & LPRGBP & $3.186 * \star *$ & LPROTH & $0.520 * \star \star$ & INDTRTEL & $-0.055 *$ & INDTRTEL & -0.019 & INDSHC & 0.041 \\
\hline LPRFBA & $0.274 *$ & LPRKK & $0.473 * \star$ & FOALQ00Z & 0.718 * & INDPROD & 0.057 * & INDPROD & $0.102 * \star *$ & MDUOLF5Z & 0.009 \\
\hline FODURE2Z & 0.224 ** & FODUROLZ & 0.081 & NCLFBQ & -0.033 & INDEWM & -0.141 & MDURUEZ & $0.173^{* \star \star}$ & NUMPR2 & $0.116^{* * *}$ \\
\hline FODUREZ & $-0.187 * * *$ & FODUREZ & -0.068 & WIEFSIN & -0.127 & INDBAIT & 0.040 & NUMPR2 & $0.190 * \star *$ & NUMPR5 & $0.070^{* \star *}$ \\
\hline DIFFRAUE & -0.342 & DIFGBP & -0.893 ** & QU1ED1 & -0.222 & MDURUEZ & 0.211 *** & NUMPR5 & $0.102 * * *$ & LPRFBA & 0.186 \\
\hline DIFCOUNS & -0.721 *** & DIFKK & -0.145 & QU1REIND & 0.222 * & NUMPR2 & $0.149 * \star *$ & FODUUE5Z & -0.145 & LPRFBT & 0.367 \\
\hline DIFSOB & -0.074 & DISDIFL & $-0.458 * * *$ & QU4REIND & -0.107 & NUMPR5 & $0.082 * * *$ & LPRCOUNS & -0.084 & LPRFBQ & $0.367^{\star \star *}$ \\
\hline DIFJOB & -0.123 & DISGBP & -0.759 * & FONUMPR2 & 0.221 * & LPRCOUNS & -0.229 ** & LPRSOB & 0.171 & LPRKK & 1.702 *** \\
\hline NCLSOB & -0.507 * & DIDUUE2Z & 0.344 & DIFBGL & $0.460 * * *$ & LPRSOB & -0.132 & LPRFBA & $0.210^{* \star *}$ & LPRUGP & 0.117 \\
\hline DISCOUNS & $-0.862 *$ & RINDAUSL & -0.340 ** & DIFNOE & -0.099 & LPRGBP & 0.283 & LPRFBT & 0.423 * & LPRUGPKK & 1.821 *** \\
\hline DISSOB & -0.878 *** & LOWREIND & 0.061 & DIFWIE & -0.228 ** & LPRFBA & $1.707 * \star *$ & LPRFBQ & $1.940 * \star *$ & LPROTH & $0.249 * \star \star$ \\
\hline DISFBQ & 0.184 & LOWRETOU & 0.182 & DIFQU4 & 0.070 & LPRFBQ & $0.628 * * *$ & |LPRKK & $0.192 * * *$ & FODUREZ & -0.042 ** \\
\hline
\end{tabular}


Table 3 continued

\begin{tabular}{|c|c|c|c|c|c|c|c|c|c|c|c|}
\hline |DISDIFL & $-0.356 * * *$ & |QU1REIND & $0.419 * * \star$ & |NUIPROD & 0.037 & |LPRKK & $0.407 * \star \star$ & |LPRUGP & 0.198 & |FODUUE2Z & -0.291 \\
\hline DISED1 & -0.274 * & QU4REIND & 0.240 & QU4OTH & -0.576 & LPRUGP & $0.535 * \star$ & LPROTH & 0.143 ** & FODUROLZ & -0.046 \\
\hline DISREIND & -0.227 & DINUMPR5 & -0.118 ** & BWIEED1 & 0.307 & LPROTH & $0.200 * \star \star$ & FOEDNO & 0.194 * & DIFFRAUE & $0.381 * * *$ \\
\hline DISINLOW & 0.239 * & DIFNOE & 0.109 & BWIEED3 & $0.816 * \star *$ & FODURE2Z & 0.036 & FOEDHI & 0.164 & DIFFBA & 0.134 \\
\hline FOSOB & 0.722 & DIFSTM & -0.298 & & & FODUREZ & 0.023 & FODUREZ & -0.034 ** & DIFKK & $-0.312 * \star *$ \\
\hline WIEDIS & -0.317 & DIFVBG & $0.401 * *$ & & & FODUUE2Z & -0.127 & FOCC2Z & -0.280 & DIFJOB & -0.091 ** \\
\hline LOWFSIN & $0.341 * \star \star$ & DIFQU1 & -0.280 ** & & & FOCCZ & 0.227 ** & FOCCZ & $0.362 * * \star$ & NCLFBA & $-0.429 * *$ \\
\hline DIFBGL & $0.696 * * *$ & DIFQU4 & 0.195 * & & & FOFRACUE & 0.080 & DIFFRAUE & $0.582 * * *$ & NCLKK & $-0.400 * \star *$ \\
\hline DIFOOE & 0.233 ** & RTOUED3 & 0.176 & & & FONOCL & 0.058 & DIFCOUNS & -0.288 & NCLFSIN & $0.133 *$ \\
\hline DIFSTM & -0.213 ** & ED3JHEA & 0.426 & & & DIFFRAUE & $0.214 * *$ & DIFFBQ & $-0.385 * * \star$ & NCLFMISS & 0.130 \\
\hline DIFQU1 & -0.254 ** & JMISED1 & -0.164 & & & DIFSOB & 0.130 & DIFJOB & -0.077 ** & DISKK & -0.165 \\
\hline DIFQU4 & 0.076 & JMISREIN & -0.324 & & & DIFFBA & $-0.259 * \star *$ & NCLFBA & -0.191 & DISDIFL & $-0.246 * \star *$ \\
\hline DIISHC & 0.156 & NCLDIFL & 0.002 & & & DIFFBQ & -0.235 *夫 & NCLFBQ & -0.230 ** & DISRETOU & 0.120 \\
\hline QU1SOB & 1.270 *** & NCLINCL & 0.160 & & & DIFKK & -0.097 & NCLFSIN & $0.116 *$ & DIDUUE2Z & $0.247 *$ \\
\hline RINDED1 & $-0.235 *$ & DIFJED1 & 0.140 & & & DIFUGP & -0.215 & NCLFMISS & -0.055 & WIEDIS & -0.133 \\
\hline MDURUE2Q & 0.215 & & & & & NCLFSIN & 0.045 & DISCOUNS & -0.216 & DITMPR5Z & -0.075 \\
\hline DIFLEMPQ & 0.038 & & & & & DIFJOB & $-0.201 * * *$ & DISFBQ & $-0.472 * * *$ & WIEFOREI & 0.010 \\
\hline FRACAMID & 0.322 ** & & & & & NCLFBA & $-0.340 * \star *$ & DISDIFL & $-0.371 * \star *$ & FONUMPR5 & 0.022 \\
\hline FRACAHIG & $0.807 * * *$ & & & & & NCLFMISS & 0.145 & DISNOCL & -0.088 & DINUMPR5 & -0.021 \\
\hline & & & & & & DISFBA & -0.070 & DISED1 & $-0.241 * \star * \star$ & DIFNOE & 0.038 \\
\hline & & & & & & DISDIFL & $-0.322 * \star *$ & DISED3 & 0.129 & DIFOOE & 0.108 * \\
\hline & & & & & & DISNOCL & -0.011 & DISINLOW & -0.024 & DIFSTM & $-0.094 *$ \\
\hline & & & & & & DISED1 & $-0.230 * \star \star$ & WIEFSIN & 0.042 & DIFVBG & 0.003 \\
\hline & & & & & & WIEFMISS & $-0.479 * \star \star$ & WIEFCOM & $0.225 * * \star$ & DIFWIE & $0.233^{* * *}$ \\
\hline & & & & & & WIEFOREI & 0.101 ** & WIEFMISS & -0.178 ** & DIFQU4 & 0.055 \\
\hline & & & & & & WIEDIS & -0.011 & RINDLZA & 0.036 & NUITCON & 0.102 ** \\
\hline & & & & & & LOWREIND & 0.092 ** & LOWREIND & 0.039 & NUICOM & 0.020 \\
\hline & & & & & & LOWRETOU & 0.166 ** & LOWRETOU & -0.124 * & QU4KK & $0.406 * \star \star$ \\
\hline & & & & & & LOWFSIN & 0.034 & LOWFSIN & $0.119 * * *$ & RINDED1 & -0.007 \\
\hline & & & & & & LOWFDIV & -0.028 & LOWFDIV & -0.030 & BWIEED1 & $0.154 * \star \star$ \\
\hline & & & & & & LOWFCOM & 0.083 & QU4REIND & $-0.099 * * *$ & BWIEED3 & 0.130 ** \\
\hline & & & & & & DIDUREZ & -0.028 & DIDUUE2Z & 0.567 *** & MDURUE2Q & $1.044 * \star *$ \\
\hline & & & & & & DIDUROLZ & -0.106 ** & DIDURUEZ & -0.180 ** & DIFLEMPQ & \\
\hline & & & & & & FOTMPR5Z & -0.006 & DITMPR5Z & $-0.216 * * *$ & & \\
\hline & & & & & & FOSOB & 1.117 ** & FOTMPR2Z & 0.230 & & \\
\hline & & & & & & FOFBA & 0.114 & FOTMPR5Z & -0.280 & & \\
\hline & & & & & & FONUMPR2 & 0.056 & FOFBQ & 0.253 ** & & \\
\hline & & & & & & DINUMPR2 & -0.089 ** & FONUMPR5 & $0.152 * \star \star$ & & \\
\hline & & & & & & DIFBGL & $0.317^{* * *}$ & DINUMPR5 & -0.038 & & \\
\hline & & & & & & DIFKTN & 0.242 ** & DIFKTN & $0.294 * \star \star$ & & \\
\hline & & & & & & DIFNOE & $0.133 * *$ & DIFNOE & $0.271 * * *$ & & \\
\hline & & & & & & DIFSTM & $0.199 * * \star$ & DIFOOE & $0.327^{* \star \star}$ & & \\
\hline & & & & & & DIFTIR & 0.156 ** & DIFSBG & $0.411 * \star \star$ & & \\
\hline & & & & & & DIFWIE & $-0.159 * \star *$ & DIFSTM & 0.185 *** & & \\
\hline & & & & & & DIFQU1 & -0.037 & DIFTIR & $0.431 * * *$ & & \\
\hline & & & & & & DIFQU4 & $0.184 * \star *$ & DIFWIE & 0.102 ** & & \\
\hline & & & & & & NUIPROD & 0.037 & DIFQU1 & -0.064 * & & \\
\hline & & & & & & NUITCON & $0.158 * * *$ & DIFQU4 & 0.054 & & \\
\hline & & & & & & NUICOM & -0.042 & NUIPROD & -0.105 ** & & \\
\hline & & & & & & NUIBAIT & 0.043 & NUITCON & 0.198 *** & & \\
\hline & & & & & & FOIPROD & 0.025 & NUICOM & -0.032 & & \\
\hline & & & & & & FOITCON & $-0.111 *$ & NUIAUTH & 0.139 & & \\
\hline & & & & & & FOICOM & 0.013 & DIIPRIM & $-0.699 * * *$ & & \\
\hline & & & & & & FOISHC & $0.390 * \star *$ & DIITOU & 0.145 & & \\
\hline & & & & & & FOITOU & 0.152 ** & RTOUED3 & 0.193 ** & & \\
\hline & & & & & & DIICOM & -0.150 ** & NCLNUMP5 & -0.038 & & \\
\hline & & & & & & QU1FBA & 0.115 & & & & \\
\hline & & & & & & QU4FBA & -0.061 & & & & \\
\hline & & & & & & QU4FBQ & -0.118 & & & & \\
\hline & & & & & & QU4KK & 0.192 * & & & & \\
\hline & & & & & & MDURUE2Q & 0.512 *** & & & & \\
\hline & & & & & & DIFLEMPQ & 0.038 * & & & & \\
\hline
\end{tabular}

Note: Positive coefficients denote that the respective variable contributes positively to the participation probability in the program listed on top of each column. $\left(^{*}\right)$ significance on the 10 percent, $\left(^{* \star}\right) 5$ percent, and $\left(^{*}\right) 1$ percent level. SEE: socio-economic enterprise. NSP: non-profit sector project, JC: job coaching, AJS: active job search, QM: qualification measure, CS: course subsidy. The abbreviations used are explained in the following Table 4. 
Table 3: Explanation of all variables

\begin{tabular}{|c|c|c|c|}
\hline Abbreviation & Description & Abbreviation & Description \\
\hline AGENTPR & Age at program entry & FOINCLOW & foreign*linclow \\
\hline AGENTMID & (agentpr>=36) and (agentpr<46) & FONOCL & foreign*noclentr \\
\hline AGENTOLD & agentpr $>=46$ & FONUMPR5 & foreign*numpr5 \\
\hline AGIOTH & agentpr*indoth & FOREIGN & Foreigner \\
\hline AGIPRIM & agentpr*indprim & FOSINGL & foreign $\star$ famsin \\
\hline ALQ00 & UE rate 2000 & FOSOB & foreign*Iprsob \\
\hline AUSLO0Z & Fraction of foreign unemployed $2000 / 10$ & FRACAHIG & frace*agentold \\
\hline BBGL & Burgenland & FRACAMID & frace ${ }^{\star}$ agentmid \\
\hline BKTN & Carinthia & FRACE & Fraction of overall observation period in employment \\
\hline BNOE & Lower Austria & FRACUE & Fraction of overall observation period in unemployment \\
\hline BOOE & Upper Austria & INDAUTH & Last employment sector: state authority \\
\hline BSBG & Salzburg & INDCOM & Last employment sector: commerce \\
\hline BSTM & Styria & INDOTH & Last employment sector: others \\
\hline BTIR & Tyrol & INDPROD & Last employment sector: production \\
\hline BVBG & Vorarlberg & INDSHC & Last employment sector: schooling, health, culture \\
\hline BWIE & Vienna & INDSHC & Last employment sector: schooling, health, culture \\
\hline BWIEED1 & bwie*ed1 & INDTCON & Last employment sector: construction \\
\hline BWIEED3 & bwie*ed3 & INDTOU & Last employment sector: tourism \\
\hline DIDUUE2Z & disab*mdurue $2 z$ & INDTRTEL & Last employment sector: transport \& telecommunication \\
\hline DIFBGL & diflempz*bbgl & JAGGR & Profession: agriculture, forestry \\
\hline DIFCOUNS & diflempz*lprcouns & JENG & Profession: engineering \\
\hline DIFFBA & diflempz*|prfba & JHEALTH & Profession: health, education, culture \\
\hline DIFFRAE & diflempz*frace & JHEDIS & jhealth*diasbled \\
\hline DIFFRAUE & diflempz*fracue & JHEED3 & jhealth*ed3 \\
\hline DIFGBP & diflempz*lprgbp & JHEFEM & jhealth*female \\
\hline DIFJED1 & diflempz* ed1 & JJUR & Profession: law, adminstration \\
\hline DIFJFEM & diflempz female & JMISED1 & jmiss*ed1 \\
\hline DIFJOB & diflempz*jobdiff & JMISEDM & jmiss*edmiss \\
\hline DIFKK & diflempz*lprkk & JMISREIN & jmiss*regind \\
\hline DIFKTN & diflempz*bktn & JMISS & Profession: missing \\
\hline DIFLEMPQ & Time in UE until program entry (squared) & JOBDIFF & Wish for vocational change \\
\hline DIFLEMPZ & Time in UE until program entry / 10 & JSERV & Profession: service \\
\hline DIFNOE & diflempz*bnoe & JTRADE & Profession: commerce \\
\hline DIFOOE & diflempz*booe & JUG00Z & Fraction of adolescent unemployed 2000 / 10 \\
\hline DIFQU1 & diflempz*quart1 & LASTINCM & Last income missing \\
\hline DIFQU3 & diflempz*quart3 & LINCLOW & Last income below median $\mathrm{y} / \mathrm{n}$ \\
\hline DIFQU4 & diflempz*quart4 & LLASTINC & Log last income \\
\hline DIFSBG & diflempz*bsbg & LOWFSIN & linclow*famsin \\
\hline DIFSOB & diflempz*|prsob & LOWREIND & linclowregind \\
\hline DIFSTM & diflempz*bstm & LOWRETOU & linclowregtou \\
\hline DIFTIR & diflempz*btir & LPRCOUNS & Last program:OM \\
\hline DIFVBG & diflempz*bvbg & LPRFBA & Last program: AJS \\
\hline DIFWIE & diflempz*bwie & LPRFBQ & Last program: QM \\
\hline DIIPRIM & disab*indprim & LPRFBT & Last program: JC \\
\hline DIISHC & disab*indshc & LPRGBP & Last program: NSP \\
\hline DIITOU & disab*indtou & LPRKK & Last program: CS \\
\hline DINUMPR5 & disab*numpr5 & LPROTH & Last program: others \\
\hline DISAB & Disability & LPRSOB & Last program: SEE \\
\hline DISCOUNS & disab*|prcouns & LPRUGP & Last program: BSU \\
\hline DISDIFL & disab*diflempz & LPRUGPKK & Last program: BSU+CS \\
\hline DISED1 & disab*ed1 & LZA00Z & Fraction long-term unemployed $2000 / 10$ \\
\hline DISFBQ & disab*lprfbq & MDUOLF2Z & Mean duration in OLF 2 years before UE entry / 10 \\
\hline DISGBP & disab*lprgbp & MDUOLF5Z & Mean duration in OLF 5 years before UE entry / 10 \\
\hline DISINLOW & disab*linclow & MDURE2Z & Mean duration in employment 2 years before UE entry / 10 \\
\hline DISKK & disab*lprkk & MDUREZ & Mean duration in employment overall before UE entry / 10 \\
\hline DISNOCL & disab*noclentr & MDUROLFZ & Mean duration in OLF before UE entry / 10 \\
\hline DISREIND & disab*regind & MDURUE2Q & Mean duration in unemployment 2 years before UE entry (squared) \\
\hline DISRETOU & disab*regtou & MDURUE2Z & Mean duration in unemployment 2 years before UE entry / 10 \\
\hline
\end{tabular}




\begin{tabular}{|c|c|c|c|}
\hline DISSOB & disab*lprsob & MOFPR & Month of pregnancy right before the hypothetical program entry \\
\hline DITMPR5Z & disab*totmpr5z & NCLCOUNS & noclentr*|prcouns \\
\hline DURLEMPH & Duration of last employment / 100 & NCLDIFL & noclentr*diflempz \\
\hline ED1 & edno+edbasic & NCLFBA & noclentr*|prfba \\
\hline ED1JHEA & ed1* jhealth & NCLFBQ & noclentr*|prfbq \\
\hline ED3 & edhigh+edacad & NCLFMISS & noclentr^fammiss \\
\hline ED3JHEA & ed3* jhealth & NCLFSIN & noclentr^famsin \\
\hline EDACAD & Academic degree & NCLINCL & noclentr*linclow \\
\hline EDADV & Vocational entrance degree & NCLKK & noclentr^|prkk \\
\hline EDMIS & Schooling Missing & NCLNUMP5 & noclentr*numpr5 \\
\hline EMPBIG & Size of last employer in persons: $[100,499]$ & NCLSOB & noclentr*|prsob \\
\hline EMPHUGE & Size of last employer in persons: >499 & NOCLENTR & No UB claim at program entry \\
\hline EMPMISS & Size of last employer in persons: missing & NUIAUTH & numpr2*indauth \\
\hline EMPSM & Size of last employer in persons: $<10$ & NUICOM & numpr2*indcom \\
\hline EPHED1 & 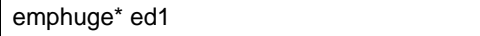 & NUIOTH & numpr2*indoth \\
\hline EPMREIND & empmissregind & NUIPROD & numpr2*indprod \\
\hline FAMCOM & Living community & NUITCON & numpr2*indtcon \\
\hline FAMDIV & Family status: divorced & NUMPR2 & Number of programs 2 years before program entry \\
\hline FAMMISS & Family status: missing & NUMPR5 & Number of programs 5 years before program entry \\
\hline FAMSIN & Family status: single & QU1GBP & quart1*|prgbp \\
\hline FECC2Z & female^totmcc2z & QU1KK & quart1*lprkk \\
\hline FEDIV & female*famdiv & QU1REIND & quart1*regind \\
\hline FEDUOL5Z & female*totmcc5z & QU1SOB & quart1*|prsob \\
\hline FEDUREZ & female*mdurez & QU4FBQ & quart4*|prfbq \\
\hline FEDUROLZ & female*mdurolfz & QU4KK & quart4*|prkk \\
\hline FEDURUEZ & female ${ }^{\star}$ mduuez & QU4REIND & quart4*regind \\
\hline FEDUUE5Z & female*mduue $5 z$ & QU4REIND & quart4*regind \\
\hline FEED1 & female*ed1 & QUART1 & Entry into UE: 1st quarter of the year \\
\hline FEED3 & female*ed2 & QUART4 & Entry into UE: 4th quarter of the year \\
\hline FEFBQ & female*|prfbq & REGIND & Industrial environment \\
\hline FEIAUTH & female*indauth & REGTOUR & Touristic environment \\
\hline FEIBAIT & female*indbait & RINDALQ & regind*alq00z \\
\hline FEICOM & female*indcom & RINDAUSL & regind*aus $100 z$ \\
\hline FEIHOU & female*indhou & RINDED1 & regind*ed1 \\
\hline FEINCLOW & female*linclow & RINDFEMA & regind*female \\
\hline FEIOTH & female*indoth & RINDLZA & regind*|za00z \\
\hline FEIPRIM & female*indprim & RTOUED1 & regtou*ed1 \\
\hline FEIPROD & female*indprod & RTOUED3 & regtou*ed3 \\
\hline FEISHC & female*indshc & TOTCOUNS & totmpr5z*|prcouns \\
\hline FEITCON & female*indtcon & TOTFBA & totmpr5z*lprfba \\
\hline FEITOU & female*indtou & TOTFBQ & totmpr5z*|prfbq \\
\hline FEITRTEL & female*indtrtel & TOTFBT & totmpr5z*|prfbt \\
\hline FEKK & female*lprkk & TOTGBP & totmpr5z*|prgbp \\
\hline FEMALE & female & TOTKK & totmpr5z*|prkk \\
\hline FENOCL & female*noclentr & TOTMCC2Z & Number of months in child care 2 years before UE entry / 10 \\
\hline FENUMPR2 & female*numpr2 & TOTMCC5Z & Number of months in child care 5 years before UE entry / 10 \\
\hline FENUMPR5 & female*numpr5 & TOTMCCZ & Number of months in child overall / 10 \\
\hline FEOTH & female*|proth & TOTMPR2Z & Number of months in programs 2 years before UE entry / 10 \\
\hline FESINGL & female*famsin & ТОТОТН & totmpr5z*|proth \\
\hline FETMPR5Z & female*totmpr5z & TOTSOB & totmpr5z*|prsob \\
\hline FOALQ00Z & foreignªlq00 & VVZ & Number of job offers / 10 \\
\hline FODURE2Z & foreignmdure2z & WIEDIS & bwie disab \\
\hline FODURE2Z & foreign*mdure $2 z$ & WIEFDIV & bwie*famdiv \\
\hline FODUREZ & foreign ${ }^{\star}$ mdurez & WIEFEMAL & bwie*female \\
\hline FODUROLZ & foreignmdurolfz & WIEFOREI & bwie*foreign \\
\hline FODUUE2Z & foreign $\star$ mduue $5 z$ & WIEFOREI & bwie*foreign \\
\hline FOEDBAS & foreign ${ }^{\star}$ edbasic & WIEFSIN & bwie*famsin \\
\hline FOFBQ & foreign*|prfbq & & \\
\hline
\end{tabular}




\section{Graphical results}

This section comprises graphical results that are mentioned in the paper, but not listed for brevity reasons.

Figure 1: Effects on unemployment by gender

Men
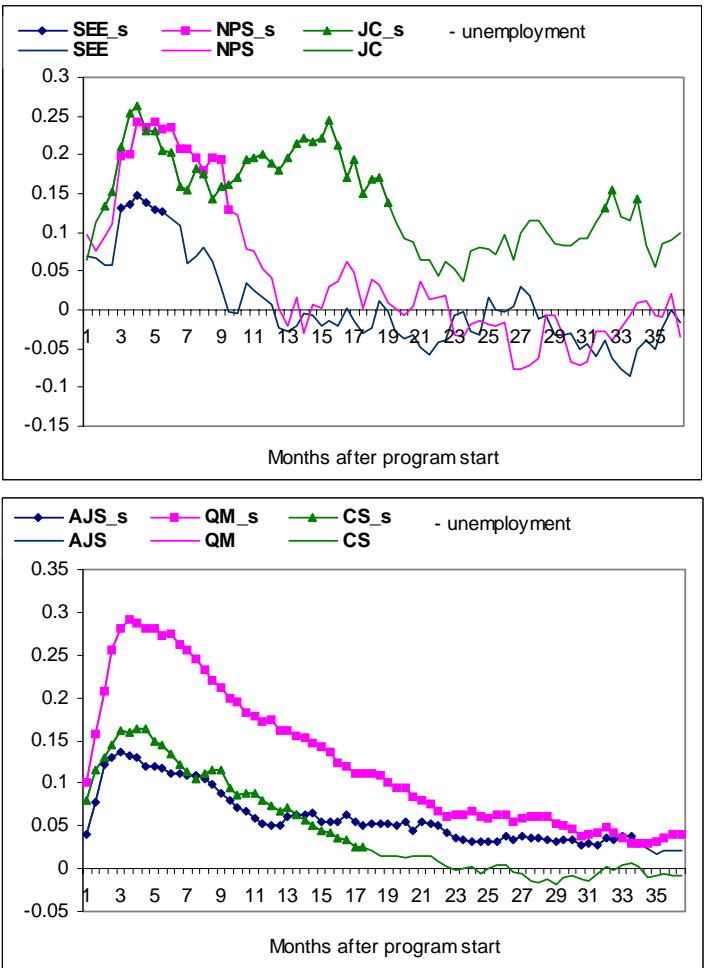

Women
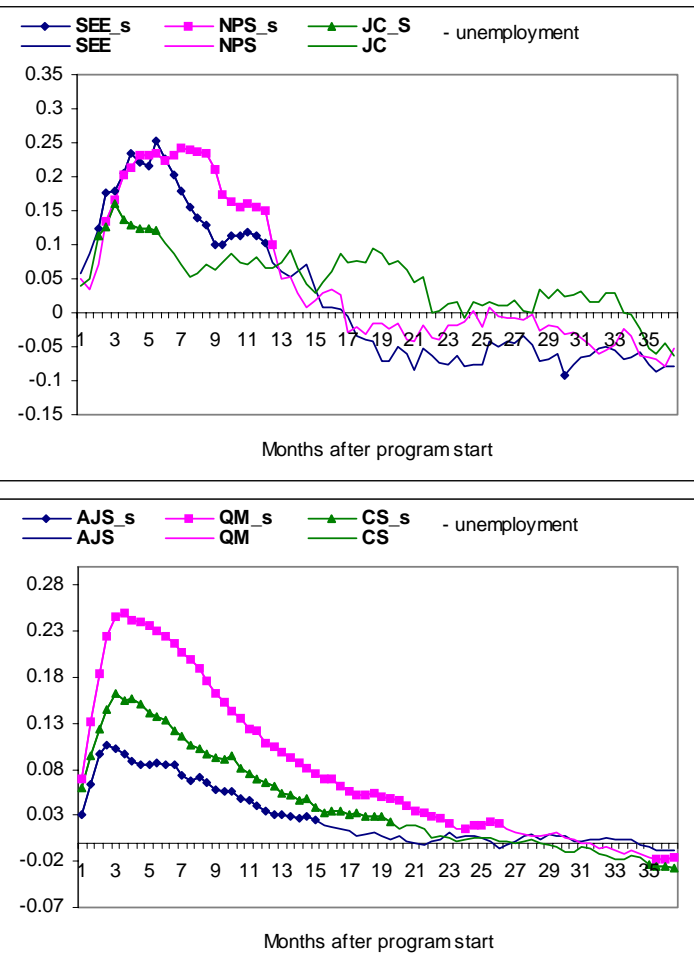

Note. Results based on matching estimation. Abscissa: Months after program entry. Ordinate: Difference of employment rates. Symbols indicate that the effect is statistically different from zero at the 95\% level. SEE: socio-economic enterprise, NSP: non-profit sector project, JC: job coaching, AJS: active job search, QM: qualification measure, CS: course subsidy. Participants (male/female): SEE (343/340), NSP (300/347), JC (206/243), AJS (9641/9638), QM (6869/11330), CS (4549/5587). 
Figure 2: Effects for men $>=40$ years on employment and unemployment
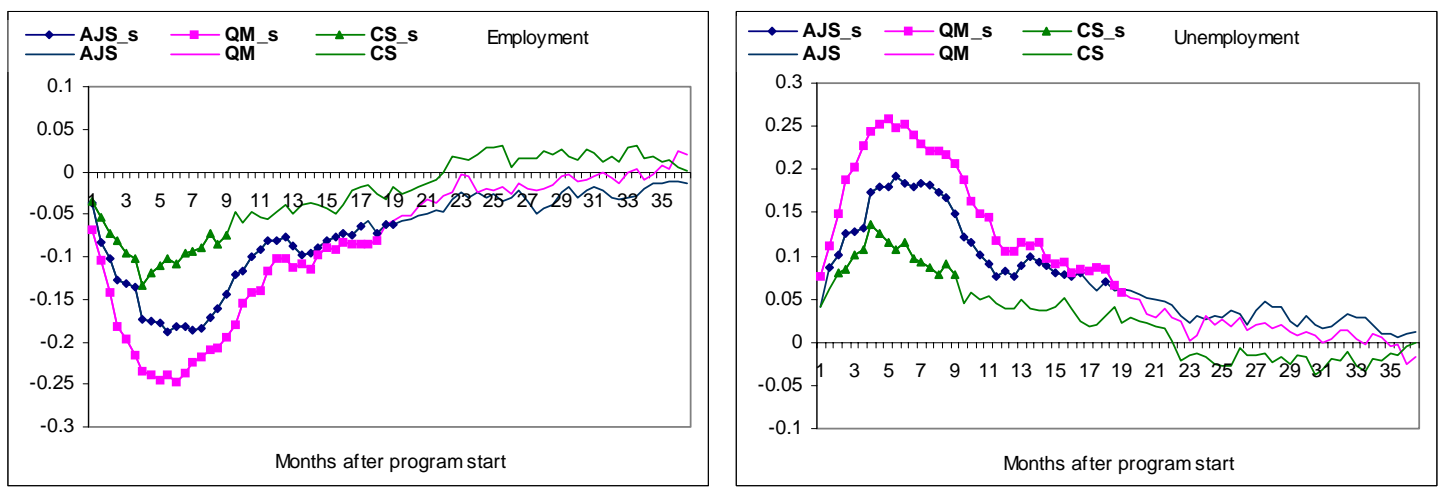

Note. Results based on matching estimation. Abscissa: Months after program entry. Ordinate: Difference of employment rates. Symbols indicate that the effect is statistically different from zero at the $95 \%$ level. AJS: active job search, QM: qualification measure, CS: course subsidy. 